FEDERAL RESERVE BANK OF SAN FRANCISCO

WORKING PAPER SERIES

\title{
Global Financial Cycles and Risk Premiums
}

\author{
Oscar Jorda \\ Federal Reserve Bank of San Francisco \\ Moritz Schularick \\ University of Bonn and CEPR \\ Alan M. Taylor \\ University of California, Davis \\ NBER and CEPR \\ Felix Ward \\ University of Bonn \\ May 2018 \\ Working Paper 2018-05 \\ http://www.frbsf.org/economic-research/publications/working-papers/2018/05/
}

\section{Suggested citation:}

Jorda, Oscar, Moritz Schularick, Alan M. Taylor, Felix Ward. 2018. “Global Financial Cycles and Risk Premiums” Federal Reserve Bank of San Francisco Working Paper 2018-05. https://doi.org/10.24148/wp2018-05

The views in this paper are solely the responsibility of the authors and should not be interpreted as reflecting the views of the Federal Reserve Bank of San Francisco or the Board of Governors of the Federal Reserve System. 


\title{
Global financial cycles and risk premiums*
}

\author{
Òscar Jordà $^{\dagger} \quad$ Moritz Schularick $\ddagger \quad$ Alan M. Taylor Felix Ward $^{\mathbb{I}}$ \\ May 2018
}

\begin{abstract}
This paper studies the synchronization of financial cycles across 17 advanced economies over the past 150 years. The comovement in credit, house prices, and equity prices has reached historical highs in the past three decades. The sharp increase in the comovement of global equity markets is particularly notable. We demonstrate that fluctuations in risk premiums, and not risk-free rates and dividends, account for a large part of the observed equity price synchronization after 1990. We also show that U.S. monetary policy has come to play an important role as a source of fluctuations in risk appetite across global equity markets. These fluctuations are transmitted across both fixed and floating exchange rate regimes, but the effects are more muted in floating rate regimes.
\end{abstract}

Keywords: financial cycles, asset prices, equity return premium, policy spillovers, financial centers

JEL Codes: E50, F33, F42, F44, G12, N10, N2O.

${ }^{\star}$ Comments and suggestions from the conference organizers, the editor, and referees have helped improve the paper. Generous support from the Institute for New Economic Thinking, the Bundesministerium für Bildung und Forschung (BMBF), and the Volkswagen Foundation supported our work. We are grateful for their support. The views expressed in this paper are the sole responsibility of the authors and to not necessarily reflect the views of the Federal Reserve Bank of San Francisco or the Federal Reserve System.

${ }^{\dagger}$ Federal Reserve Bank of San Francisco; and Department of Economics, University of California, Davis (oscar.jorda@sf.frb.org; ojorda@ucdavis.edu).

‡Department of Economics, University of Bonn; and CEPR (schularick@uni-bonn.de).

$\S$ Department of Economics and Graduate School of Management, University of California, Davis; NBER; and CEPR (amtaylor@ucdavis.edu).

II Department of Economics, University of Bonn; (felix.ward@uni-bonn.de). 


\section{INTRODUCTION}

The Global Financial Crisis highlighted the need for an evolution in macroeconomic thinking. Added to the urgency to integrate banking and finance into the basic architecture of macroeconomic models, one could add that there is a also fundamental need to understand the financial cycle and its interplay with the business cycle. But is there a financial cycle at all? And if so, how has its operation in the global economy evolved?

The first goal of this paper is to fill some gaps in our knowledge by analyzing global financial cycles over the past 150 years across a sample of 17 advanced economies. While the comovement of real variables has been extensively studied in the literature, financial cycles have received less attention. This is partly due to the fact that long-run data for credit growth, house prices, and equity prices have only recently become available (Jordà, Knoll, Kuvshinov, Schularick, and Taylor, 2017a; Jordà, Schularick, and Taylor, 2016).

Our analysis reveals that the synchronization of financial cycles across countries has become increasingly prevalent. We can now speak of a global financial cycle whose effects are felt widely and more vividly over the past few decades than ever before. For the most part, financial synchronization has increased hand in hand with international synchronization of real variables, such as GDP, consumption and investment. Equity price synchronization follows a different pattern, however, and we find a much more rapid increase in global synchronicity since the 1990s. Moreover, we find that this rise in equity price synchronicity exceeds that of dividends, whose international comovement is more in line with the cyclical comovement in real variables. The explanation for this divergence is the striking rise in the volatility and global covariation of equity return premiums, and principally the risk premiums embedded therein. Our analysis thus lends support to accounts that put asset prices and risk premiums at center stage in explaining the synchronization of the global economy (Dedola and Lombardo, 2012; Devereux and Yetman, 2010; Dumas et al., 2003; Fostel and Geanakoplos, 2008; Ward, 2018). ${ }^{1}$

The second goal of this paper is to analyze the role that monetary policy plays in explaining the increased synchronization of global risk appetite. In particular, we find that U.S. monetary policy is a powerful driver of global risk appetite and thus binds together global equity prices. Moreover, we show that this synchronization of international risk taking is a new phenomenon. In contrast, in the first era of globalization, before 1914, we

\footnotetext{
${ }^{1}$ Dumas et al. (2003) explain the excessive correlation of equity prices over fundamentals through the excessive volatility of a common stochastic discount factor.
} 
do not find evidence for linkages in risk appetite internationally. Possible explanations include current monetary practice and a more prominent role of leveraged financial intermediaries, dollar fundings markets, and global banks in the world economy today.

A natural international transmission channel is via exchange rates and hence we evaluate whether our findings on synchronicity are stronger for countries with fixed exchange regimes relative to countries that allow their exchange rate to float freely (see section 4.4). We find some evidence that the transmission effects are stronger for fixed exchange rate regimes, but they are still sizable for floaters. This finding adds an important new dimension to the debate about the degree to which international financial integration undermines monetary policy autonomy. In the case of equity markets, there is suggestive evidence that monetary policy in the center country triggers swings in risk appetite that appear to be independent of domestic monetary conditions.

Links between our findings and the existing literature are numerous. First, we add a longer-run cross-country perspective to the existing financial cycle literature, such as Claessens et al. (2011), Drehmann et al. (2012), as well as Aikman et al. (2014) and Schüler et al. (2015). Second, we confirm recent research regarding the increase in global financial synchronization over the past two decades (e.g. Bruno and Shin, 2014; Cerutti et al., 2014; Obstfeld, 2014). Our data provide evidence in support of this trend towards increased financial synchronization. Third, we extend the literature that studies the relation between financial- and real-cycle comovements (see Meller and Metiu, 2017). Fourth, our work builds on an emerging literature that investigates the nexus between monetary policy and risk taking, asset prices, and global financial synchronization (Miranda-Agrippino and Rey, 2015).

\section{FINANCIAL AND REAL CYCLE SYNCHRONIZATION, 1870-2013}

\subsection{Data}

The data that we use in this paper come from a number of sources. GDP, consumption and investment data come from the latest vintage of the Jordà, Schularick, and Taylor (2016) Macrohistory Database (available at www.macrohistory.net/data). The dataset comprises annual data from 1870 to 2013, for 17 countries: Australia, Belgium, Canada, Denmark, Finland, France, Germany, Italy, Japan, the Netherlands, Norway, Portugal, Spain, Sweden, Switzerland, U.K. and the U.S.. Combined, these 17 countries make up more than $50 \%$ of world GDP throughout the period we consider. 
Financial cycles are associated with the synchronized ebb and flow in credit aggregates, house prices, and equity prices across countries (see Aikman et al., 2014; Claessens et al., 2011; Drehmann et al., 2012). The credit series cover loans of all monetary financial institutions-including savings banks, postal banks, credit unions, mortgage associations, and building associations - to the non-financial private sector.

To study equity- and house-price comovements we rely on the newly collected dividend and rental yield series introduced by Jordà, Knoll, Kuvshinov, Schularick, and Taylor (2017a). The equity premium is defined as the excess total return of equity over short-term government bonds. Detailed explanations on how these data were constructed are available in that paper.

\subsection{Methods}

To analyze the international comovement of real and financial cycles in this study our most basic measure of coherence for real and financial cycles is a 15-year rolling-window Spearman rank correlation coefficients. We prefer this to the more traditional Pearson correlation as it captures monotone but not necessarily linear relationships. The appendix reports results based on rolling-window Pearson correlation coefficients, which turn our to be qualitatively similar. The 15-year rolling-windows that we use are backwardlooking, that is, the correlation coefficient reported for 2000 is based on data from 1986 to 2000. Hence, we denote the Spearman correlation coefficient between countries $i$ and $j$ calculated over the 15 -year window ending at time $t$ as $s_{t}^{i, j}$ for $i, j=1, \ldots n$, where $n$ is the cross-sectional sample size. A global measure of association can then be constructed as the average of these bilateral correlations as follows:

$$
\bar{s}_{t}=\frac{\sum_{i} \sum_{j<i} s_{t}^{i, j}}{N} ; \quad N=\frac{n(n-1)}{2} .
$$

In terms of notation, $t$ is the rolling-window time index defined earlier, $\bar{s}_{t}$ is the average bilateral correlation coefficient at $t$ and $s_{t}^{i, j}$ is the bilateral correlation coefficient for countrypair $i, j$. The number of distinct correlations excluding the correlation of one country with itself is given by the usual formula $n(n-1) / 2$ where $n$ is the total number of countries in the sample. In order to account for the cross-sectional and temporal dependencies, all confidence intervals are constructed using a cross-sectional block-bootstrap procedure (see Kapetanios, 2008). 
As a robustness check, we also construct a GDP-weighted average version of expression (1). In particular, we use the relative purchasing power-adjusted real GDP of the bilateral country pair $i, j$, that is,

$$
\begin{aligned}
\bar{s}_{t}^{\omega} & =\sum_{i} \sum_{j<i} \omega_{i, j, t} s_{t}^{i, j}, \quad \text { with } \\
\omega_{i, j, t} & =\frac{\left(G D P_{i, t}+G D P_{j, t}\right)}{\sum_{i} \sum_{j<i}\left(G D P_{i, t}+G D P_{j, t}\right)},
\end{aligned}
$$

where $G D P_{i, t}$ denotes country $i$ 's GDP at time $t$. Results based on this GDP-weighted measure are generally very similar to those based on the unweighted measure described in expression ( 1 ) and are therefore reported in the appendix.

Next, note that to isolate the cyclical component in the series of our database we rely on the Baxter-King band-pass filter. ${ }^{2}$ Financial cycles are typically characterized by relatively low frequency movements, with one cycle lasting between 8 to 16 years according to Drehmann et al. (2012), while Schüler et al. (2015) find important variation in credit cycles well above the 20 year periodicity. Results by Cagliarini and Price (2017) in contrast suggest that financial cycles are not necessarily longer than business cycles. Also, equity prices, which are also of interest here, exhibit much larger short-term variation. As a way to accommodate these divergent views, we take a conservative approach and therefore focus on a broad cycle-band ranging from 2 to 32 years. Before detrending, we CPI-deflate each series and take its logarithm.

As a robustness check, we also report results based on an alternative nonparametric detrending method recently suggested by Hamilton (forthcoming). This approach relies on the observation that, unlike short-lived cyclical fluctuations, trend components are the only feature of the data that can be predicted at longer horizons. Yet another approach is to put more weight on high-frequency annual changes. This has the advantage of not having to rely on a pre-processing filtering step. Hence, we study annual growth rates (total loans, house prices, credit prices, GDP, consumption, investment, dividends) and first differences (real short-term rates, equity return premiums). Finally, we calculate concordance indices as proposed by Harding and Pagan (2002) in order to address concerns about heteroskedasticity bias in correlation coefficients (see Forbes and Rigobon, 2002). The concordance measure indicates the fraction of years in which two series

\footnotetext{
${ }^{2}$ In the subsequent correlation analysis we detrend all series with the exception of interest rates and equity return premiums, which are stationary in the long run.
} 
move into the same direction. It abstracts from the size of such movements, rendering it immune to heteroskedasticity bias. The appendix shows consistent results using these alternative approaches for completeness.

\subsection{Financial and real synchronization}

This section presents the 15-year rolling window correlation results for the financial and real variables that have been introduced in section 2.1. All variables have been detrended as described in section 2.2. Figure 1 displays the average bilateral correlation of three financial variables - real credit (measured by total loans), real house prices, and real equity prices-for the 17 country sample. Comovement in credit- and equity price-cycles has risen substantially over time. In particular, the comovement of credit and equity markets is at a historical peak today, with Spearman correlation coefficients of about 0.4 and 0.8 respectively. Abstracting from the bouts of house price comovement associated with WWI and WW2 housing busts, international house prices are also more correlated today than before, but the divergence in global house prices since the financial crisis has dampened synchronization in recent years. The rise in equity price correlation to near unity since the 1990 is particularly striking as it exceeds even the correlation in asset prices during the declines associated with the Great Depression. The comovement in credit, house prices, and equity prices is higher in the past few decades than in previous periods. In this sense it is possible to speak about a global financial cycle among developed economies. But how does this compare to the long-run synchronization of real cycles in GDP, consumption, and investment?

Figure 2 shows that the comovement of cycles in real variables also exhibits an upward trend since the start of the sample. The cyclical behavior GDP across countries is a good example - even accounting for the blip up due to the Great Depression (see Bordo and Helbling, 2003). GDP today exhibits an average bilateral correlation of somewhat above 0.5 , its highest value since 1870 . Similarly, the consumption correlation has trended upward nearly on a par with GDP, although today it is slightly lower than the correlation for GDP (see Backus et al., 1992). The international comovement of investment had already been relatively high in the late 19th and early 2oth centuries, but by the 2000 s the comovement in investment reached a new peak.

International synchronization of the financial and real sectors of economies have increased in tandem. At some level this is to be expected. Globalization forces would tend to increase integration in the real economy and with it, the financial sector. However, as 
Figure 1: Average bilateral financial cycle correlation

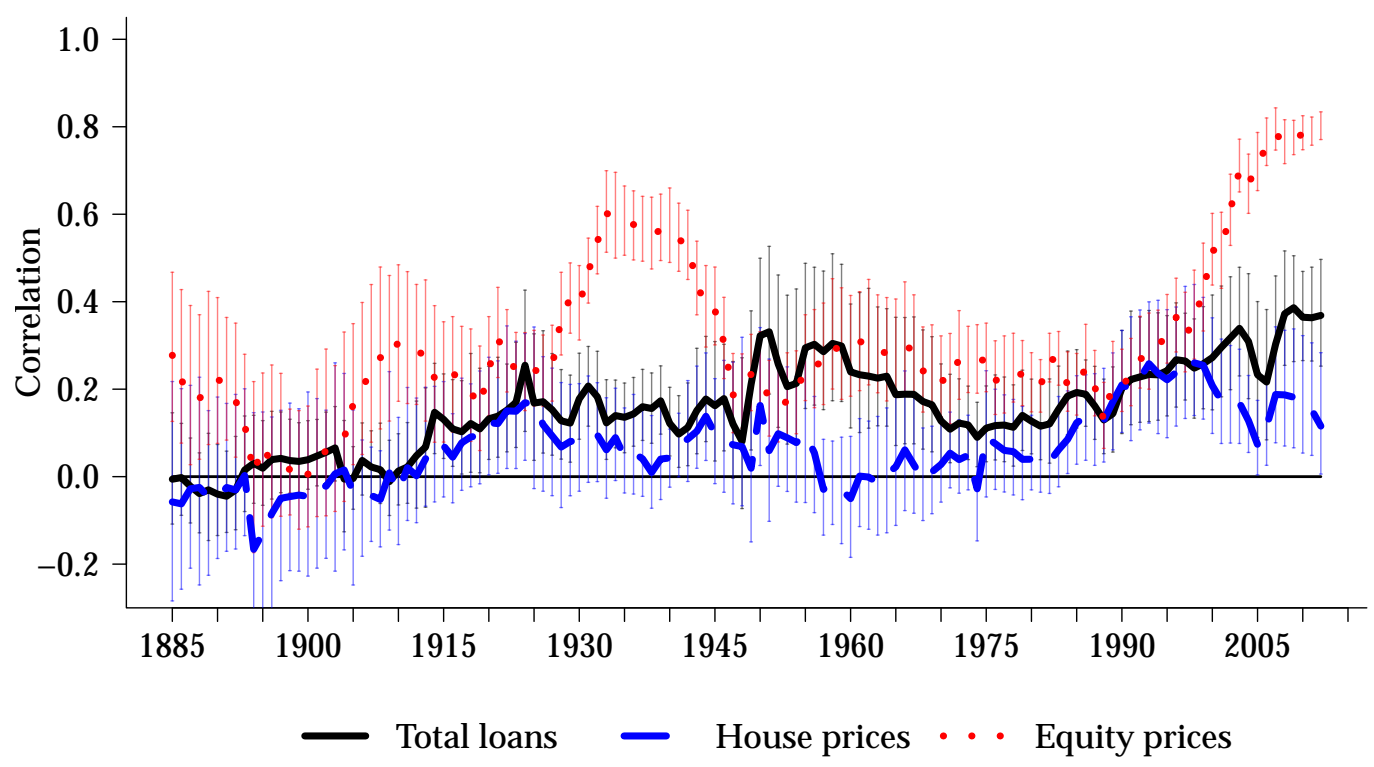

Notes: Spearman rank correlation coefficients based on 15-year rolling windows. 2 to 32 -year period BaxterKing detrended series. Bars $-95 \%$ cross-sectionally block-bootstrapped confidence bands.

Figure 2: Average bilateral real economy correlation

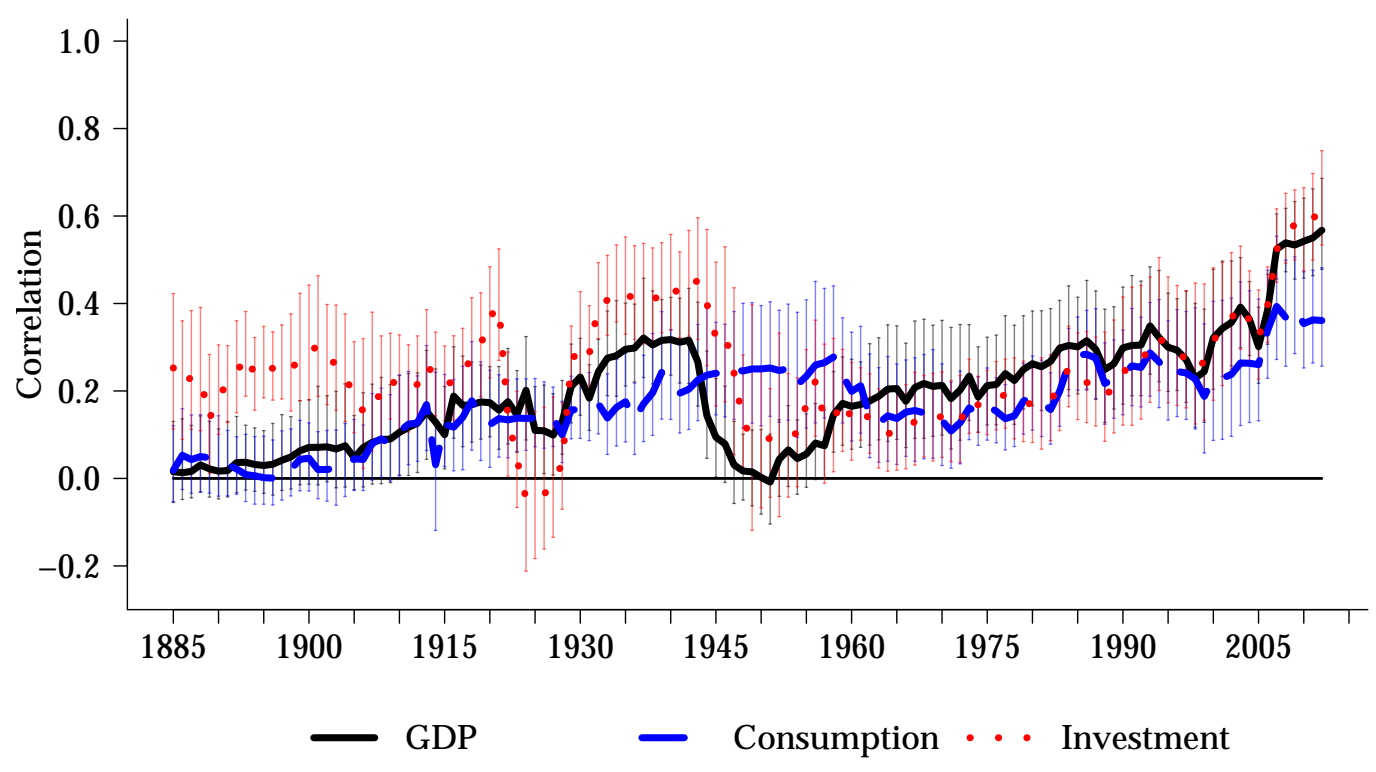

Notes: Spearman rank correlation coefficients based on 15-year rolling windows. 2 to 32-year period BaxterKing detrended series Bars $-95 \%$ cross-sectionally block-bootstrapped confidence bands. 
Figures 1 and 2 illustrate, it looks as if the comovement in equity prices has outstripped the comovement in other variables. This finding is robust to different detrending methods, as well as other synchronization measures (see figure A.4 to A.10 in the appendix).

Within our sample, some geographical regions exhibit more real and financial synchronization than others (see Figures A.11 to A.14 in the appendix). Within the euro area and within Scandinavia for example, GDP, consumption, and investment have reached average bilateral correlation levels close to o.8 over the past decades. In the case of Scandinavia, dividend comovement can explain more of the late 2oth century increase in equity price correlation than it can in other regions. Finally, even within the Pacific region (Australia, Canada, Japan and the U.S.) equity price correlation has increased to around 0.7 since the late 2oth century, despite there being virtually zero correlation in dividends.

Summing up, we document a substantial increase in the comovement of equity prices that is only partly matched by increasing real sector linkages. In the following sections, we will take a closer look at the drivers of the rising comovement in international equity markets.

\section{UNDERSTANDING EQUITY MARKET COMOVEMENT}

\subsection{Correlation in dividends, risk-free rates, and return premiums}

To get a first impression of the sources that lie behind the recent and dramatic increase in the international comovement of equity prices this section describes the international comovement of different equity price determinants: dividends, risk-free rates, and equity return premiums. Figure 3 shows the average bilateral correlation between short-term and long-term risk-free rates, $R$. Figure 4 shows the average bilateral correlation between dividends, $D$, and the equity return premium, ERP.

Figure 3 shows that the average bilateral correlation in short- and long-term interest rates follow a similar time path. Interest rate correlation has been high in the 1980s and 2000s, and relatively low in the 1990s. Interest rate correlation was also high in the $1920 \mathrm{~s}$ and 1930s. With the exception of the high-inflation era of the 1970s and 1980s, phases of high interest rate comovement thus tend to accompany phases of high equity price comovement. However, in contrast to equity price comovement after 1990, interest rate comovement has not reached historically unprecedented levels.

Figure 4 shows that the increases in equity price comovement in the 1920 s and 2000 s were also accompanied by a significant increase in the comovement of dividends and 
Figure 3: Average bilateral interest rate correlations

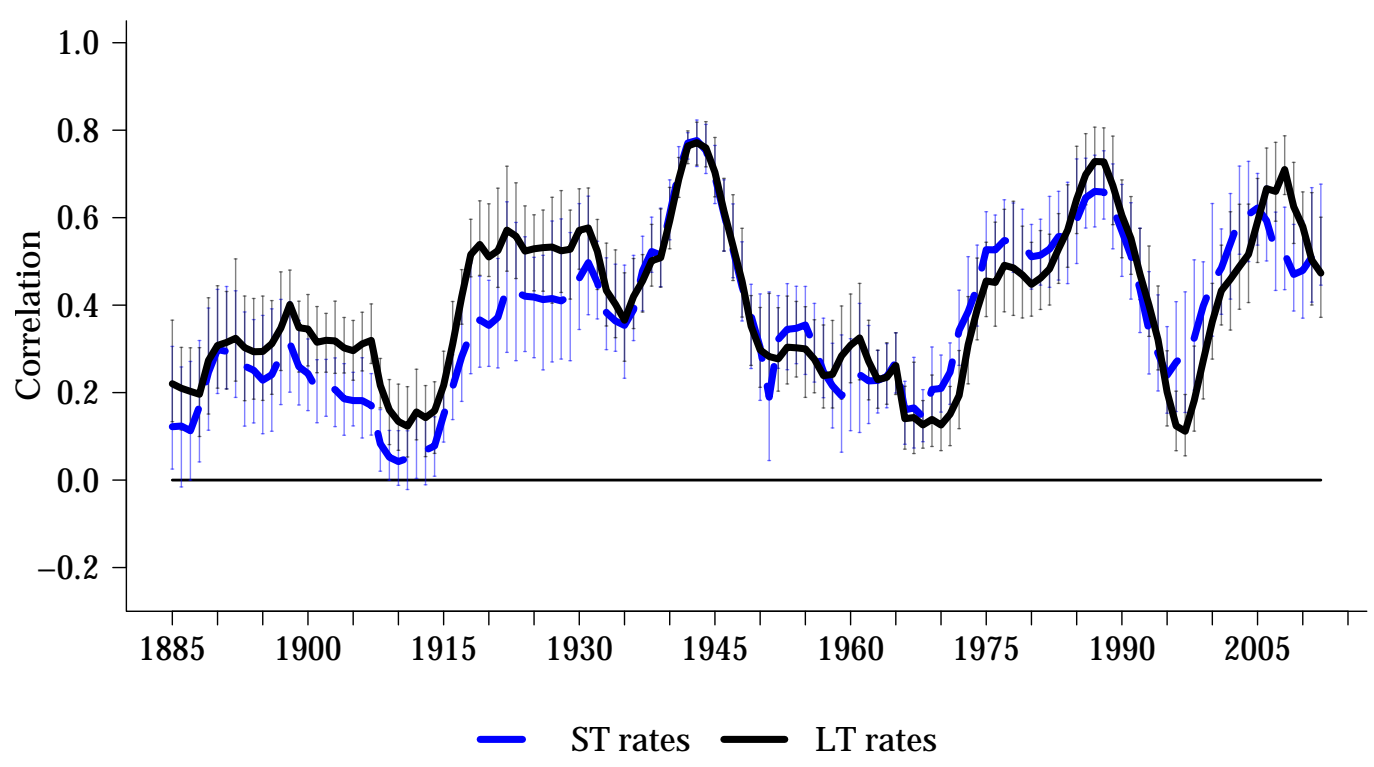

Notes: Spearman rank correlation coefficients based on 15-year rolling windows. Based on real interest rates, calculated as nominal rates minus CPI-inflation. Bars - 95\% cross-sectionally block-bootstrapped confidence bands. $S T$ refers to real short-term and $L T$ to real long-term rates respectively.

Figure 4: Average bilateral dividend and equity return premium correlations

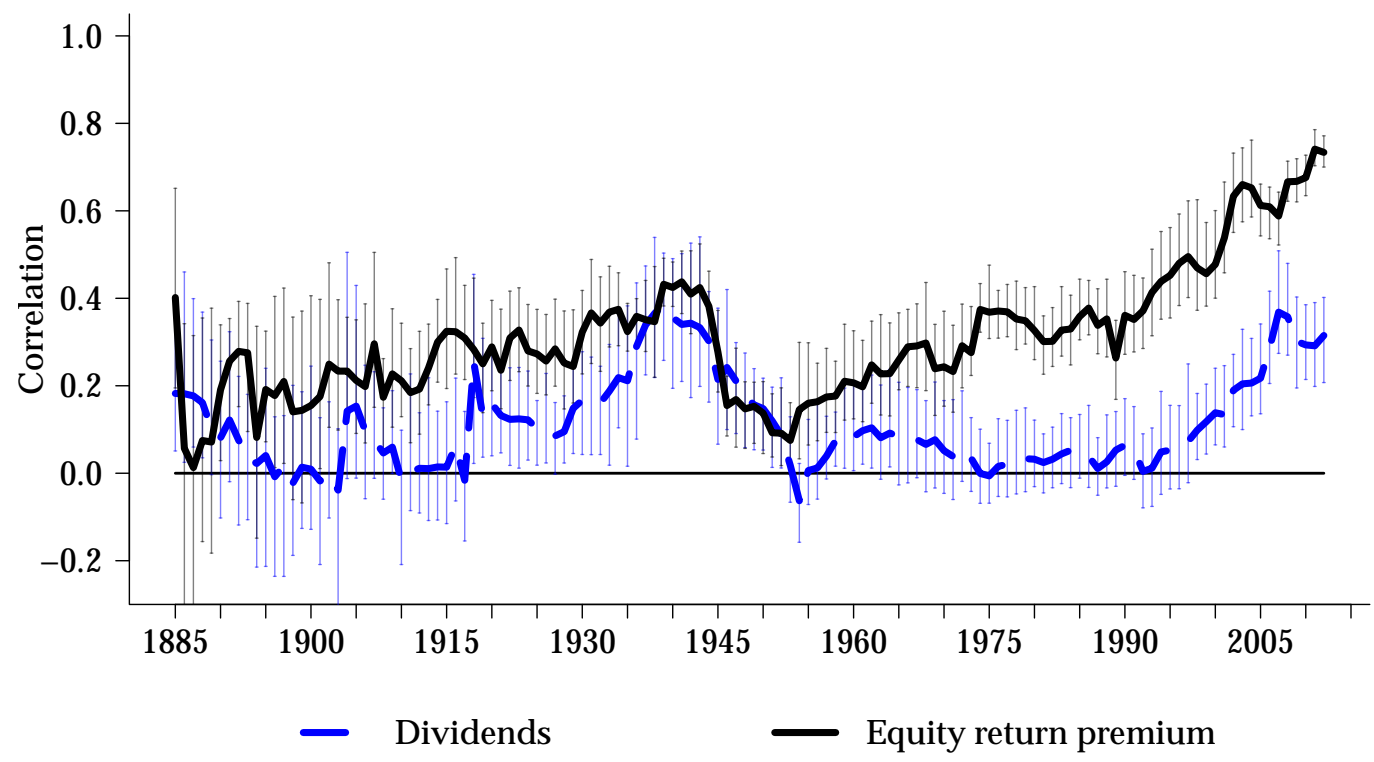

Notes: Spearman rank correlation coefficients based on 15-year rolling windows. Dividends: 2 to 32-year period Baxter-King detrended series. Equity return premium: total equity returns minus short-term riskfree rate. Bars $-95 \%$ cross-sectionally block-bootstrapped confidence bands. 
equity return premiums. The comovement of dividends peaked around 0.3 in the 200os, coming close to its 1930 seak. The international correlation of equity return premiums, however, has reached historically unprecedented levels, rising from around 0.3 to 0.8 .

These results suggest that the rising comovement of equity return premiums, ERP, may hold the key to understanding today's strong equity price synchronization. Various robustness checks, shown in the appendix, suggest that the finding that the comovement in equity return premiums has reached a historically unprecedented high is robust to different detrending methods (see figures A.4 to A.10 in the appendix).

\subsection{Equity price comovement and risk appetite}

According to standard asset pricing theory, equity prices are a function of expected future discounted dividends. Thus, in this section we take a look at whether equity price comovement can be explained by the comovement in future dividend streams discounted by future risk-free rates. Let $Q^{R N}$ be the asset price as counterfactually valued by a risk-neutral investor who prices an asset according to the present value of future dividends $D$ discounted by risk-free rates $R=1+r$ :

$$
Q_{t}^{R N}=E_{t}\left\{\sum_{k=1}^{\infty}\left(\prod_{j=1}^{k-1} R_{t+j}^{-1}\right) D_{t+k}\right\} .
$$

Furthermore, denote the remaining spread between actual asset prices $Q_{t}$ and the counterfactual risk-neutral investor's price $Q^{R N}$ as $\rho$ :

$$
Q_{t}=Q_{t}^{R N} \rho_{t}
$$

In the following analysis, we will call the term $\rho$ "risk appetite". Of course "risk appetite" thus defined is a summary term, that encompasses all factors that drive a spread between discounted dividends $Q^{R N}$ and actual equity prices $Q$. As such, "risk appetite" as we use it here embodies a diverse range of forces, such as consumption habits, the ability of intermediaries to supply loans as well as investor sentiment (see Shiller (1981a) and Galí and Gambetti (2015) for similar decompositions).

Using this basic asset pricing machinery, we can then ask the following question: How much comovement in equity prices is due to comovement in the risk-neutral investor price? And how much is due to the remainder - "risk appetite"? For this we calculate 
$Q^{R N}$ on the basis of future realized dividends and risk-free rates, assuming a terminal value at the sample end of $\frac{1}{1-\Delta \bar{D} / \bar{R}}$, where $\Delta \bar{D}$ indicates the sample median growth rate of CPI-deflated dividends, and $\bar{R}$ is the sample average of gross short-term safe rates. Given the terminal value we then calculate $Q^{R N}$ recursively through $Q_{t-1}^{R N}=D_{t} / R_{t}+Q_{t}^{R N} / R_{t}$ (see Shiller, 1981a,b). ${ }^{3}$

Note that the asset pricing equation (3) is formulated in expectations. Here we follow Shiller $(1981 a, b)$ in equalizing ex-ante expected values with their ex-post realized values. In the following, an important caveat to be aware of is that the ex-post realized values cease to be good indicators of their ex-ante expected counterparts whenever expectation errors become large. However, even if expectation errors play a role, seeing how much equity price comovement would have been justified by ex-post realized fundamentals is nevertheless interesting. A more elaborate decomposition that attempts to model expectations through a vector autoregression (VAR) system is presented in Appendix C (the decomposition is based on the methodology laid out in Ammer and Mei, 1996; Campbell, 1991; Campbell and Shiller, 1988). The results of this VAR decomposition are in line with the results of the more accessible analysis discussed in the remainder of this section. ${ }^{4}$

How much of total equity price comovement can be attributed to ex-post realized dividends and risk-free rates? Figure 5 shows that until the 1990 s the comovement in actual equity prices is mostly accounted for by the comovement in the risk-neutral investor prices $Q^{R N}$, i.e., dividends and risk-free rates. After that, however, equity price comovement starts to escape its fundamentals. After 1990, the risk-neutral price measure $Q^{R N}$ turns out to account for only about one third of the comovement in equity prices $Q$. As a result of the realized covariance between future dividends and risk-free rates, $Q^{R N}$ turns out to justify a smaller share of equity price comovement than might have been guessed from the comovement in risk-free rates and dividends. Post-1990 equity price comovement cannot be accounted for by dividends and risk-free rates; rather, it is equity return premiums that increasingly bind together equity prices among developed economies.

\footnotetext{
${ }^{3}$ While the terminal value influences the level of $Q^{R N}$ at the end of the sample, the comovement results, which are based on the detrended $Q^{R N}$, look very similar for a broad range of terminal value assumptions.

${ }^{4}$ For detrending methods that put more weight on year-to-year changes, the discrepancy between actual equity price comovement, and risk-neutral price comovement decreases (see figure A.4 to A.1o in the appendix). This suggests that dividends and risk-free rates are better at explaining equity price comovement in the short-term than in the medium-term, where discrepancies between the comovement implied by the risk-neutral price measure and actual equity prices can build up.
} 
Figure 5: Average bilateral equity price correlation

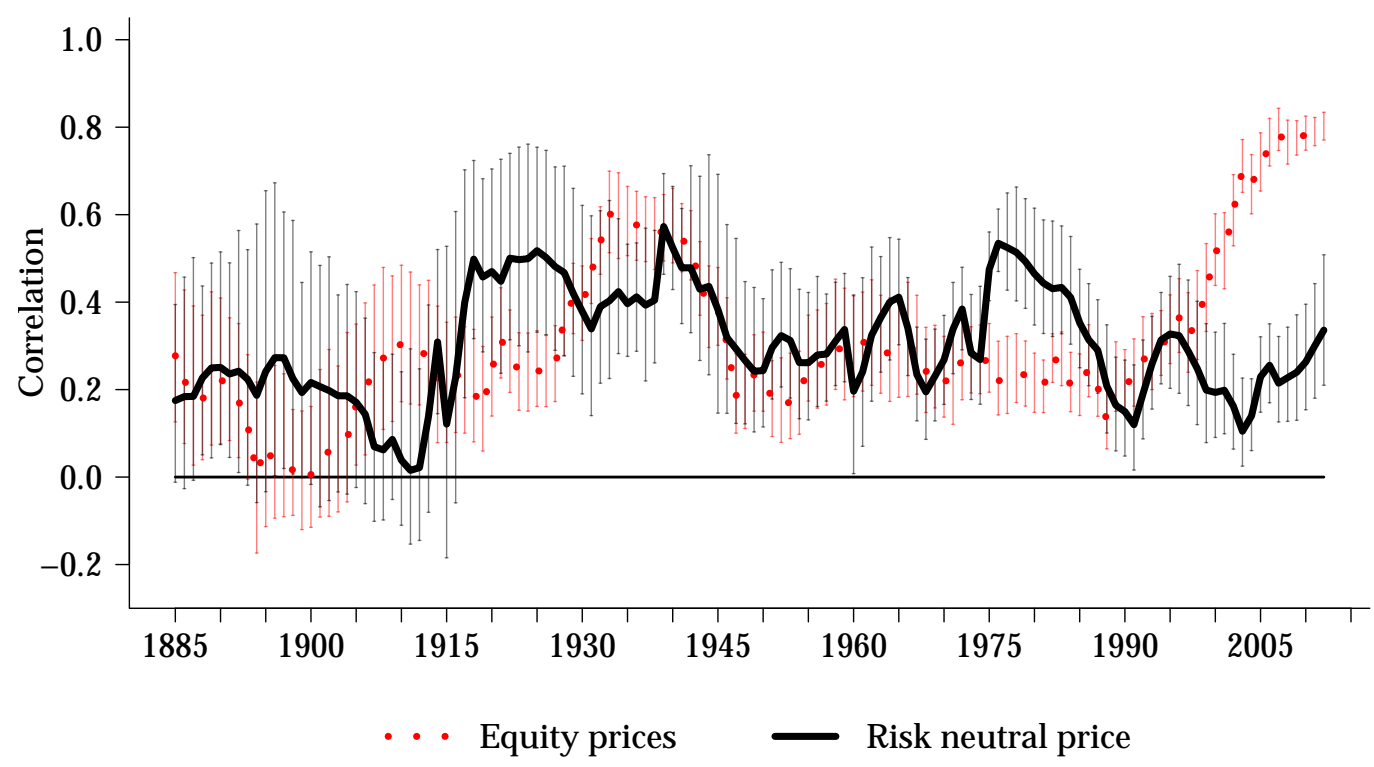

Notes: Spearman rank correlation coefficients based on 15-year rolling windows. 2 to 32-year period BaxterKing detrended series. Bars $-95 \%$ cross-sectionally block-bootstrapped confidence bands.

We are not the first to document that international equity price comovement in the late 2oth century has become increasingly dominated by factors other than dividends and risk-free rates. Ammer and Mei (1996) and Engsted and Tanggaard (2004) report related findings for the U.S. and U.K. stock markets and Jordà et al. (2017a) report similar results for the economies in our sample. More recently, Miranda-Agrippino and Rey (2015) have shown that a substantial part of global asset returns since the 1990s can be explained by one global factor that is closely and inversely related to measures of market volatility and risk aversion. With this paper, we are the first to show that this is a novel development in the history of international financial integration that was not present in the first era of global finance.

\section{MONETARY POLICY AND SYNCHRONIZATION OF RISK TAKING}

What might explain the increasing synchronization of risk appetite across global equity markets? A popular view, often embraced by practitioners in financial markets, is that monetary policy in global financial centers, in particular the Federal Reserve, plays an important role in explaining risk-taking in international financial markets. 
Such effects can occur through different channels as existing studies argue (Bekaert et al., 2013; Miranda-Agrippino and Rey, 2015). Fed policy may internationally synchronize the balance sheet capacity of financial intermediaries through its effect on asset prices (Ward, 2018). U.S. monetary policy may also directly act as a focal point that synchronizes risk perceptions of international investors (see Bacchetta and van Wincoop, 2013). The U.S. dollar is also an important vehicle currency and funding currency that underpins today's global financial system (Shin, 2012). U.S. monetary policy decisions may thus have global reach (Canova, 2005; Kim, 2001). Ehrmann et al. (2011) show that about $30 \%$ of the fluctuations in euro area financial markets can be attributed to U.S. financial market fluctuations. Theoretically, Bruno and Shin (2014) propose a model in which global banks, with access to the financial center's wholesale money markets, transmit the financial center's financing conditions to regional banks around the world. Cetorelli and Goldberg (2012) present related econometric evidence on how global banks contribute to the international transmission of liquidity shocks through the lending conducted by their foreign affiliates.

\subsection{Methods}

To investigate whether monetary policy interventions in center countries are a driver of global risk appetite, we estimate a set of cumulative impulse response functions using local projections (Jordà, 2005). ${ }^{5}$ We begin with the following specification:

$$
\Delta_{h} y_{i, t+h}=\alpha_{i}^{h}+\sum_{k=1}^{5} \beta_{k}^{h} \Delta y_{i, t-k}+\sum_{k=0}^{5} \gamma_{k}^{h} \Delta R_{t-k}^{c}+\sum_{k=0}^{5} \delta_{k}^{h} X_{i, t-k}+u_{i, t+h}, \quad h=1, \ldots, H,
$$

where $\alpha_{i}$ are country-fixed effects, $\Delta_{h} y_{i, t+h}=y_{i, t+h}-y_{i, t-1}$ is, by our convention, the $h$-year cumulative growth rate of $y, \Delta R^{c}$ is the first difference in the center country's short-term rate, $X_{i}$ is vector of control variables and $u_{i, t+h}$ are error terms. The parameters $\left\{\gamma_{0}^{h}\right\}_{h=1, \ldots, H}$ in expression (5) allow us to trace out the trajectory of equity prices, divi-

5It is reasonable to expect a certain degree of cross-sectional dependence in an international macroeconomic dataset, because countries are likely to be influenced by common disturbances. Also typical of macroeconomic data, these disturbances are likely to exhibit temporal persistence. In order to account for such cross-sectional and temporal dependencies in our data we calculate confidence bands based on Driscoll-Kraay standard errors with five autocorrelation lags (Driscoll and Kraay, 1998). Driscoll-Kraay standard errors are a nonparametric technique that is robust to very general forms of dependencies across time and space. The technique is well suited to our macroeconomic dataset, because it relies on large- $T$ asymptotics, without placing any restrictions on the limiting behavior of the number of countries. 
dends, and risk-free rates over the $H$ years following a center country interest rate change $\Delta R_{t}^{c}$. Note that this specification allows for a contemporaneous effect of the controls and center rate changes on the outcome variable.

Our impulse variable is the change in policy in the financial center, $\Delta R^{c}$. Later, we will corroborate the results with monetary policy "shock" measures, thus capturing the unanticipated part of policy changes in recent decades. The idea is to account for potential cross-country endogeneity contamination.

The U.S. was not always the world's financial center country. In the 19th century the U.K.'s financial system and currency played a similarly central role. The measure $R^{c}$ is therefore the U.K. short-term rate prior to 1914 and the U.S. short-term rate after 1947. During the interwar years, the U.S. became the world's most important financial center according to some metrics, while the U.K. retained this title until WW2 according to others (see Chiţu et al., 2014). Hence, we construct $R^{c}$ as the average of U.S. and U.K. short-term rates for the interwar years.

The control variables are five lags of log differences of GDP, CPI, equity prices, house prices, total loans, as well as housing return premiums, equity return premiums, and short-term rates. We additionally control for five lags of the center country's growth rates in per capita GDP and inflation. Finally, we also include the center country's equity prices into the vector of controls as Rigobon and Sack (2004) document that the Fed tends to raise rates when the stock market has gone up and vice versa (also see Bjørnland and Leitemo, 2009; Castelnuovo and Nisticò, 2010; Chadha et al., 2004; Furlanetto, 2011).

Moreover, in order to test whether financial center monetary policy explains the increase in the comovement of equity return premiums and risk appetite we separate the equity price impulse responses into two parts. Log-linearizing equation (3) around a balanced growth path yields an expression that can be used to calculate that part of the equity price response which is justified by the dividend and real rate responses, $Q^{R N}$ (see Galí and Gambetti, 2015):

$$
q_{t}^{R N}=\sum_{k=1}^{\infty}\left(\frac{\bar{D}}{\bar{R}}\right)^{k}\left[\left(1-\frac{\bar{D}}{\bar{R}}\right) E_{t}\left\{d_{t+k-1}\right\}-E_{t}\left\{r_{t+k}\right\}\right]+k,
$$

where small letters denote the logarithms of the original variables, $\bar{D}$ is the gross dividend growth rate along the balanced growth path, $\bar{R}$ is the respective interest rate, $\bar{D} / \bar{R} \equiv C<1$ and $k$ denotes a linearization constant (see Cochrane, 2005, p.395). In the following we set C to 0.96 . 
Consider the response to a center country interest rate intervention $\Delta R_{t}^{c}$. On the basis of expression (6) we can calculate the equity price (cumulative) response that is implied by any given dividend and interest rate response as:

$$
\sum_{k=0}^{\infty} \frac{\partial q_{t+k}^{R N}}{\partial R_{t}^{c}} \Delta R_{t}^{c}=\sum_{j=1}^{\infty} C^{k}\left[(1-C) \sum_{k=0}^{\infty} \frac{\partial d_{t+k+j-1}}{\partial R_{t}^{c}} \Delta R_{t}^{c}-\sum_{k=0}^{\infty} \frac{\partial r_{t+k+j}}{\partial R_{t}^{c}} \Delta R_{t}^{c}\right] .
$$

The difference between the cumulative response in actual equity prices $Q$ and the cumulative response implied by dividends and risk-free rates $Q^{R N}$ reflects the response of time-varying risk appetite $\rho$. For the practical calculation of the cumulative risk-neutral price response the infinite sums for the dividend and risk-free rate responses have to be replaced by a finite sum. We opted for seven-year cumulative responses because the dividend and risk-free rate responses are statistically indistinguishable from zero at higher time horizons.

Note that, as in section 3, we equalize ex-ante expected dividends and risk-free rates with their ex-post realized counterparts. We challenge this assumption in a robustness check in Appendix C, where we model expectations through a VAR system, and thus separate expected changes in dividends, risk-free rates, and return premiums from news about these variables. The conclusions we can draw from this robustness check are in line with our main results presented here.

\subsection{The response of global equity markets}

Figure 6 shows the response in percent changes of equity prices $(Q)$ and risk-neutral equity prices $\left(Q^{R N}\right)$, as well as the dividend- $(D)$ and interest rate $(R)$ responses from which the $Q^{R N}$-response was derived. The risk-neutral response (labelled "Risk-neutral" in the figure) is the response that shows how a risk-neutral investor would value equity on the basis of future dividends that are discounted with the risk-free rate. The left column in Figure 6 shows the full sample results, while the right column focuses on the post-1980 subsample in order to focus on the period of rising comovement in global risk appetite.

Our first key result is that the response of equity prices has become stronger over time. The international response to a +1 ppt center interest rate hike has almost doubled from the full sample average of about $-4 \%$ to the post-1980 trough of $-8 \%$. Furthermore, the negative response has grown more persistent. 
Figure 6: Decomposing the global equity market response
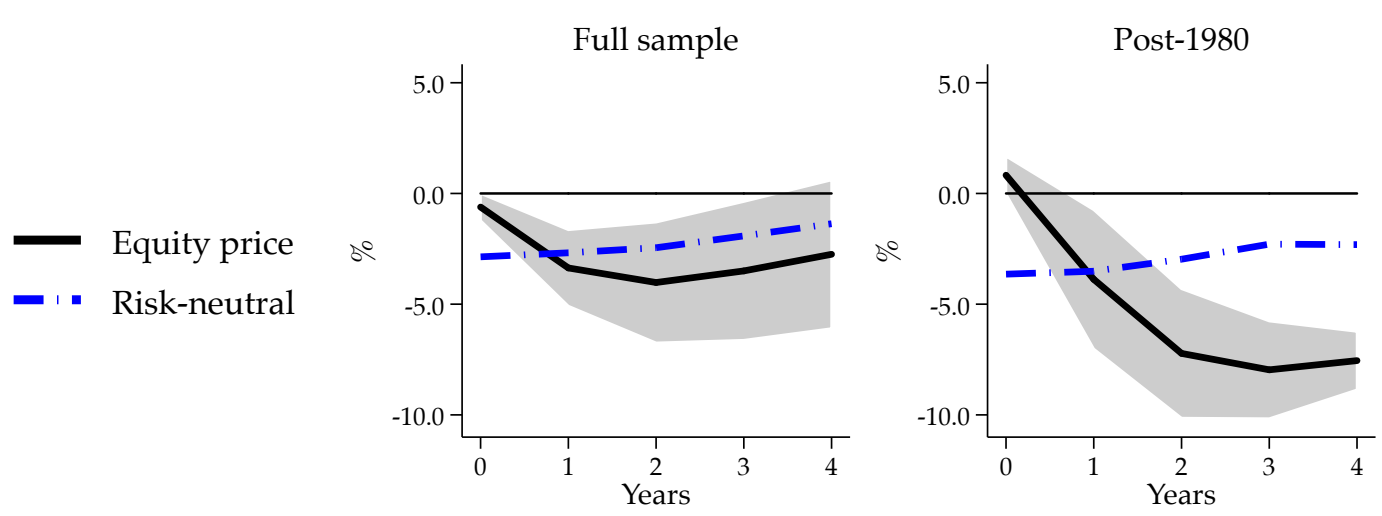

Dividend
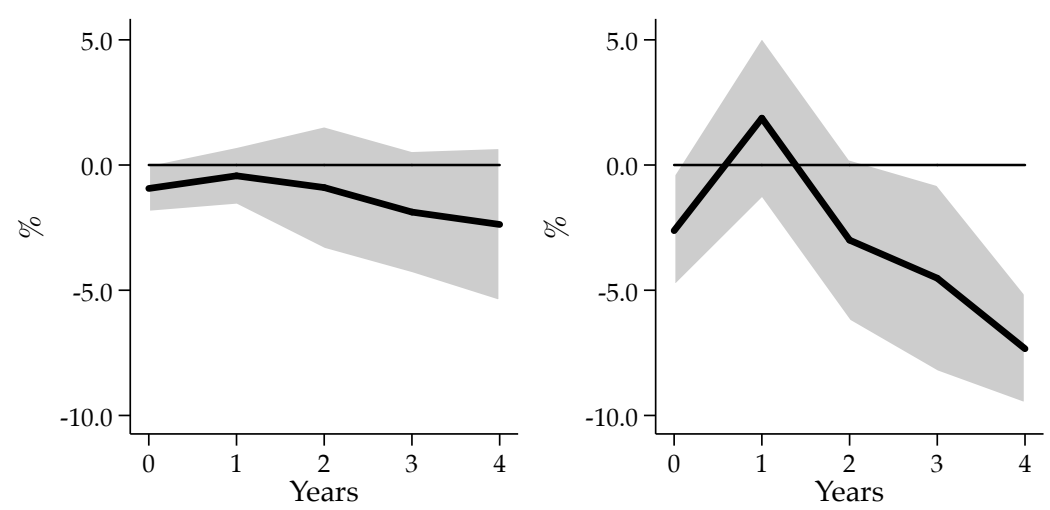

Risk-free rate
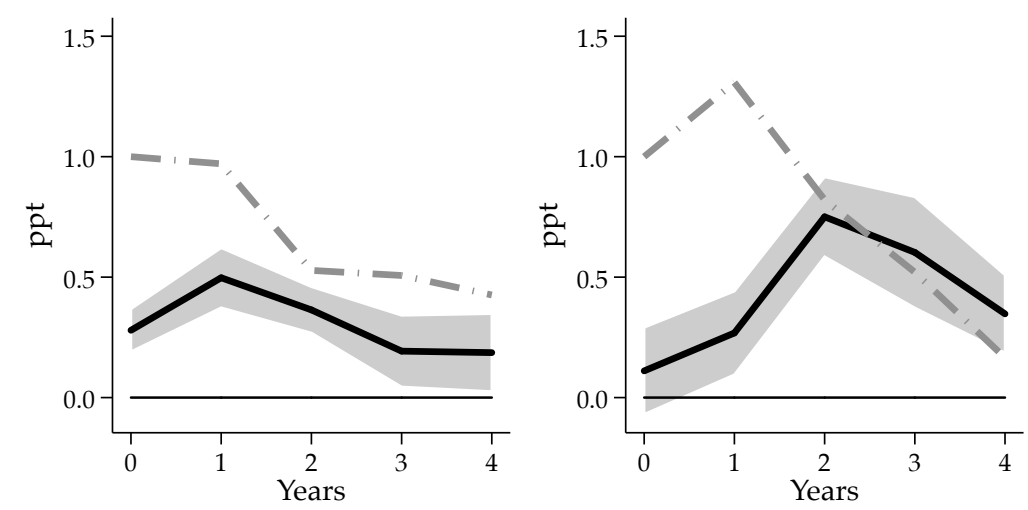

Notes: Cumulative impulse response functions to +1ppt increase in financial center interest rates. Riskneutral - risk neutral price $\left(Q^{R N}\right)$. Center rate - financial center (U.K. and/or U.S.) short-term risk-free rate own response. Confidence bands calculated on the basis of Driscoll-Kraay standard errors. Risk neutral price $\left(Q^{R N}\right)$ calculated according to equation (7). 
Figure 7: Pre-1914 vs. Post-1980 equity price responses

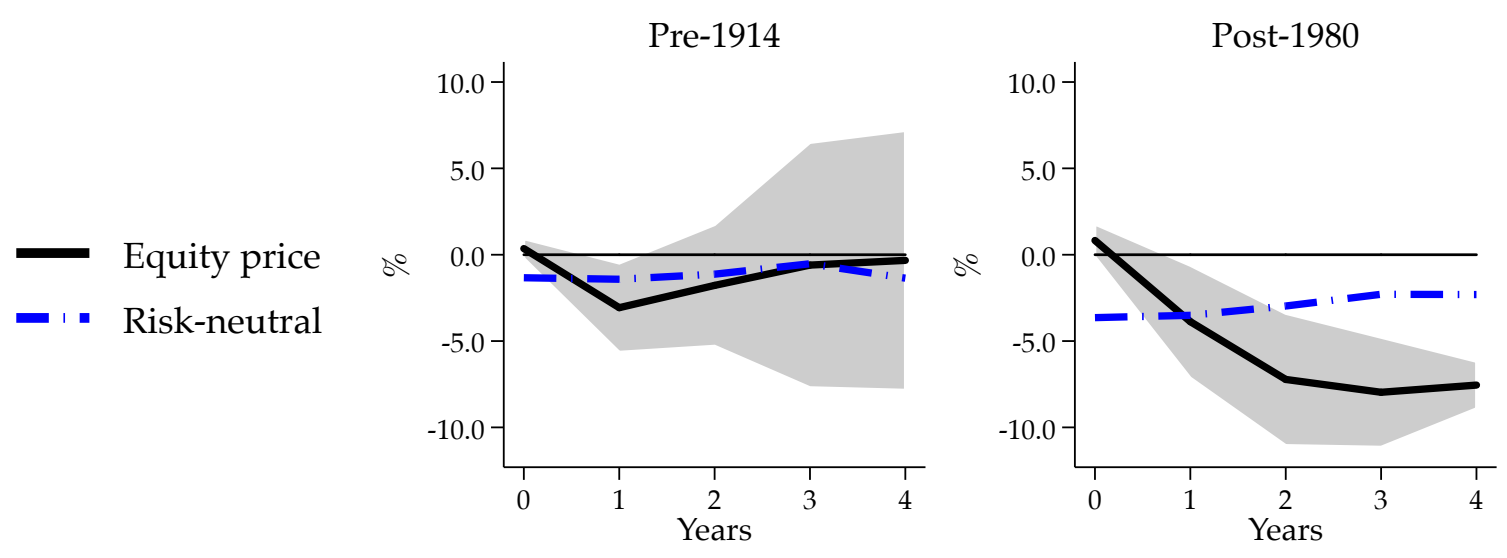

Notes: Cumulative impulse response functions to +1ppt increase in financial center interest rates. Riskneutral - risk neutral price $\left(Q^{R N}\right)$. Center rate - financial center (U.K. and/or U.S.) short-term risk-free rate own response. Confidence bands calculated on the basis of Driscoll-Kraay standard errors. Risk neutral price $\left(Q^{R N}\right)$ calculated according to equation (7).

Partly this is due to international dividends and real short-term rates having become more sensitive to changes in U.S. monetary policy. In the full sample dividends fell on average by about $2.5 \%$ and interest rates peaked at $0.5 \mathrm{ppt}$. Since 1980 the respective numbers have gone up to $5 \%$ and 0.75 ppt respectively. Stronger global dividend and real rate reactions to U.S. monetary policy, however, are insufficient to explain the stronger equity price responses.

The implied risk-neutral equity price $Q^{R N}$, calculated according to equation (7) from the dividend and interest rate responses alone, suggests that dividend and safe rate responses explain only about $25 \%$ of the post- 1980 equity price response over 4 years. Fluctuations in risk appetite are by far the most important driver, accounting for three quarters of the response.

Moreover, Figure 7 shows how much stronger the response has become from one globalization era to the next. Before 1914, equity markets reacted to rate changes much as would be expected from a risk-neutral investor. Equity prices declined in response to a $100 \mathrm{bp}$ increase of the policy rate of the Bank of England, but there is no major impact above and beyond the risk neutral path. In the post-1980 globalization, this effect is magnified by the effect on risk appetite. 


\subsection{Expected equity return premium responses}

So far we have looked at the reaction of global risk appetite to center-country policy shocks only indirectly, by separating the fundamental component $Q^{R N}$ from the actually realized equity price response $Q$. The resulting difference between the two responses indicates changes in risk appetite. Alternatively, we can look at the direct response of the equity return premium, ERP. The difficulty here is that we are interested in the ex-ante expected equity return premium that international investors require, as a measure of global risk appetite. However, we only observe the ex-post realized equity return premium.

In order to get a sense of the response of the ex-ante expected equity return premium to center-country monetary policy changes we propose a strategy that allows us to derive a lower bound estimate of the response of ex-ante expected equity return premiums from their ex-post realized counterparts. Specifically, the $h$-period ahead expected equity return premium $E_{t}\left(E R P_{t+h}\right)$, for $h=0,1,2, \ldots, H$, can be decomposed into the ex-post realized equity return premium $E R P_{t+h}$ and an expectation error $\eta_{t+h}$ :

$$
\underbrace{E_{t}\left(E R P_{t+1+h}\right)}_{\text {ex-ante expected ERP }}=\underbrace{E R P_{t+1+h}}_{\text {ex-post realized ERP }}-\eta_{t+h}
$$

Recall the ex-post realized equity return premium is $E R P_{t+1}=\frac{Q_{t+1}+D_{t+1}}{Q_{t}}-R_{t+1}$. In order to determine how the ex-ante expected equity return premium reacts to center-country monetary policy changes, we need to know how the expectation error $\eta_{t}$ reacts.

Under rational expectations, the expectation error is fully explained by exogenous innovations to the shock process and is restricted to the period in which the shock occurs, i.e. $\eta_{t+h}=0$ for $h>0$. Thus, we only need an estimate for the expectation error in the contemporaneous period, $\eta_{t}$, in order to translate the ex-post realized $E R P$ response into the ex-ante expected ERP response.

An estimate for $\eta_{t}$ can be obtained by assuming that the contemporaneous response of the ex-ante expected $E R P$ is 0 , a conservative estimate as will be discussed in a moment:

$$
\frac{\partial E_{t}\left(E R P_{t+1}\right)}{\partial R_{t}^{c}} \Delta R_{t}^{c}=0
$$

This implies that, up to a first order Taylor approximation, the estimated contemporaneous response of the ex-post realized ERP constitutes an estimate of the contemporane- 
ous expectation error $\eta_{t}:^{6}$

$$
\eta_{t}=\frac{\partial E R P_{t+1}}{\partial R_{t}^{c}} \Delta R_{t}^{c}-\frac{\partial E_{t}\left(E R P_{t+1}\right)}{\partial R_{t}^{c}} \Delta R_{t}^{c}=\frac{\partial E R P_{t+1}}{\partial R_{t}^{c}} \Delta R_{t}^{c} .
$$

On the basis of this estimate for $\eta_{t}$, the cumulative response of the ex-ante expected $E R P$ can simply be calculated as the cumulative response of the ex-post realized ERP shifted by the expectation error $\eta_{t}$ :

$$
\underbrace{\sum_{h=1}^{H} \frac{\partial E_{t}\left(E R P_{t+h}\right)}{\partial R_{t}^{c}} \Delta R_{t}^{c}}_{\text {expected ERP response }}=\underbrace{\sum_{h=1}^{H} \frac{\partial E R P_{t+h}}{\partial R_{t}^{c}} \Delta R_{t}^{c}}_{\text {realized ERP response }}-\eta_{t} .
$$

Note that the resulting impulse response function estimate constitutes a lower bound estimate, in the sense that most empirical studies on the effects of monetary policy on risk premiums and risk taking suggest that within the first 12 months after a contractionary monetary policy shock risk premiums are up and risk appetite is down (see Bekaert et al., 2013; Bernanke and Kuttner, 2005; Bruno and Shin, 2015; Gertler and Karadi, 2015). Thus, assuming a 0 contemporary response in the ex-ante expected ERP (see equation 9) is conservative.

Figure 8 depicts the resulting impulse response function estimates for the ex-ante expected ERPs (solid black line), ex-post realized ERPs (dashed blue line), as well as equity prices for various subsamples. The figure shows that the global impact of financial center-country monetary policy on global equity prices is mostly a post-WW2 phenomenon, and especially a post-1980 one. Within the post-WW2 sample, the global response of the ERP grows stronger over time, with equity prices decreasing by about $10 \%$ from trend value after a $1 \mathrm{ppt}$ Fed rate hike. The expected ERP that investors require to hold equity increases by 5 to 10 ppts. In light of these results, U.S. monetary policy is indeed a powerful driver of return premiums in global equity markets.

\subsection{Exchange rate regimes}

Risk-appetite spillovers of US monetary policy are substantial. Do floating exchange rates help countries avoid such spillovers? Floating exchange rates are thought to insulate domestic interest rates from foreign interest rates. But it is unclear whether this insulation

\footnotetext{
${ }^{6}$ This is assuming that innovations to center-country rates are not correlated with other shocks. For correlated shocks the contemporaneous response reflects expectation errors related to different shocks.
} 
Figure 8: Equity prices and equity return premiums
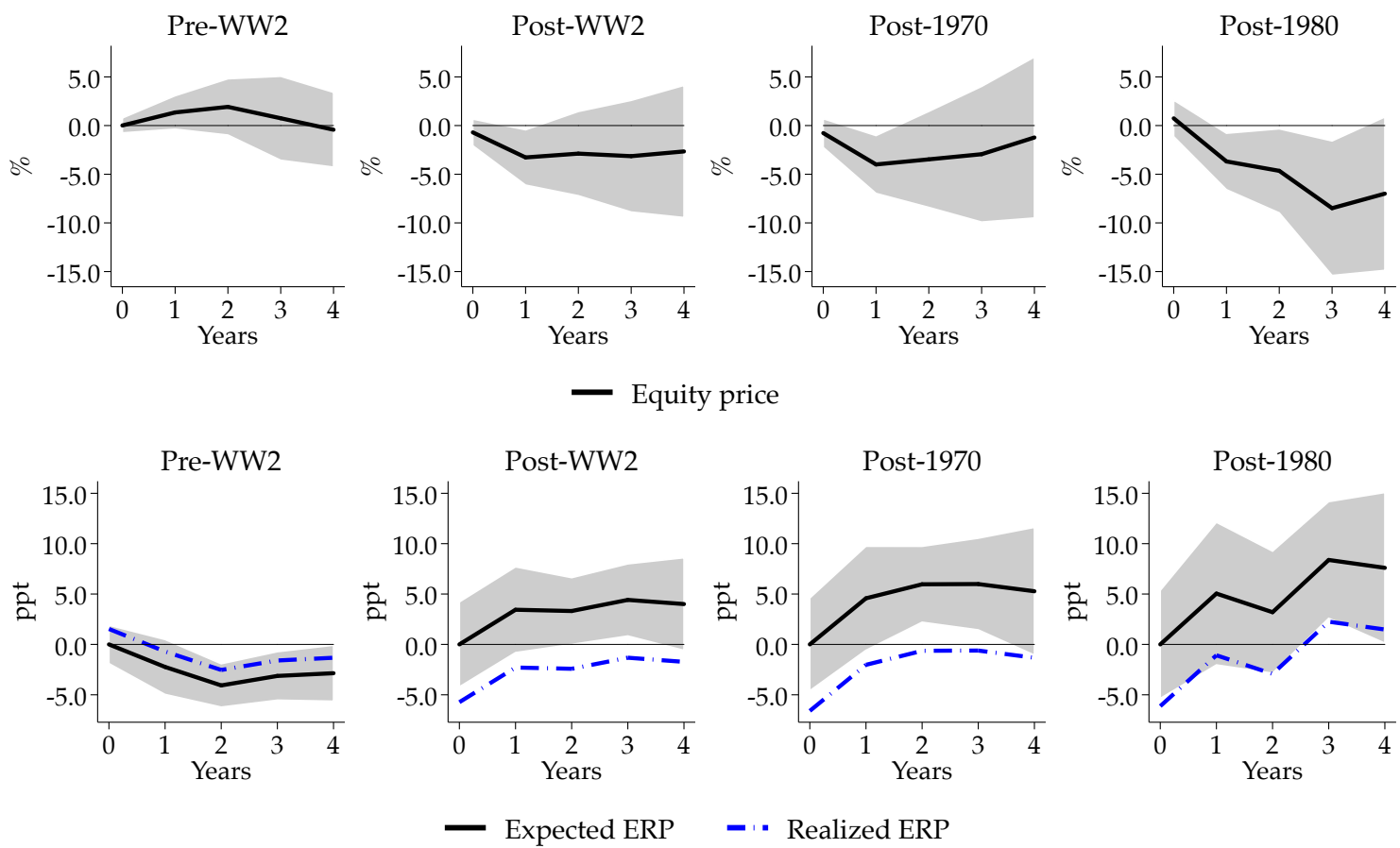

Notes: Cumulative impulse response functions to +1 ppt increase in financial center interest rates. Confidence bands calculated on the basis of Driscoll-Kraay standard errors.

generalizes to risk premiums and risk appetite more generally. It is natural to ask the extent to which floating exchange rates effectively decouple domestic financial conditions from substantial comovements in risk appetite. To address this question we condition our previous analysis on a country's exchange rate regime.

The classification of the exchange rate regime has occupied international economists for a long time (Klein and Shambaugh, 2015). Before WW2 we define our peg-float dummy variable following Obstfeld et al. (2004) and Obstfeld et al. (2005); thereafter we rely on the exchange rate regime classification scheme of Ilzetzki et al. (2017) for 1940-1959, and the Shambaugh exchange rate classification dataset for 1960-2014 (Klein and Shambaugh, 2008; Obstfeld et al., 2010; Shambaugh, 2004).

Our peg dummy takes the value of 1 if a country was on the gold standard before 1940. From 1940 onwards, it takes the value of 1 for economies whose exchange rate stays within $\mathrm{a}+/-2 \%$ band, and is o otherwise. We follow Obstfeld et al. (2005) in not considering one-off realignements as breaks in the peg regime. Similarly, single-year pegs 
are recoded as floats, as they quite likely simply reflect a lack of variation in the exchange rate.

Using this exchange rate indicator, we estimate local projections according to the following specification:

$$
\begin{aligned}
\Delta_{h} y_{i, t+h} & =\alpha_{i}^{h}+\sum_{k=1}^{L} \beta_{k}^{h} \Delta y_{i, t-k}+\sum_{k=0}^{L} \gamma_{k}^{h} \Delta R_{t-k}^{c} \\
& +\sum_{k=0}^{L} \delta^{h} \Delta R_{t-k}^{c} \times \text { float }_{i, t}+\sum_{k=0}^{L} \phi_{k}^{h} X_{i, t-k}+u_{i, t-1+h}, \quad h=1, \ldots, H,
\end{aligned}
$$

where $\alpha_{i}$ are country-fixed effects, $\Delta_{h} y_{i, t+h}$ are $h$-year changes the dependent variable and $u_{i, t+h}$ are error terms.

The $\left\{\gamma_{0}^{h}\right\}_{h=1, \ldots, H}$ in expression (12) trace out the average response of international equity prices over the $H$ years following a center-country policy rate shock $\Delta R^{c}$. The $\left\{\delta_{0}^{h}\right\}_{h=1, \ldots, H}$ capture the difference in the response between pegs and floats. float $t_{i, t}$ is a dummy variable that is 1 in periods when the exchange rate with respect to the centercountry floats, has been floating for the previous 3 years, and will be floating for the following 4 years (i.e. the entire projection horizon). Analogously the dummy is o in years when the exchange rate is fixed in the current year, was fixed throughout the previous 3 years and continued to be fixed in the 4 years to come. This definition ensures that estimated impulse response functions clearly distinguish between pegs and floats. In all cases we make use of the bilateral peg dummy describing the exchange rate regime status between any country and the center-country. In addition to the control variables used previously (see equation (5)) $X$ we also include a binary indicator for the existence of capital controls. The capital control dummy is described in detail in Jordà, Schularick, and Taylor (2015).

Figures 9 and 11 show the international responses of equity prices and ERP for the full sample. The equity price- and ERP responses tend to be stronger for countries whose exchange rate is pegged to the USD. Over the full sample, equity prices are down by $3 \%$ in year 1 , while there is no significant response among floats. On average pegs' risk appetite still tends to be more affected than floaters' risk appetite although the effects are weak. Tables 1 and 3 show the impulse responses for pegs and floats and the p-value for a Wald-test for equality of the impulse responses. The tests confirm that historically the response to center-country monetary policy changes has been significantly more pronounced for pegs. 
Table 1: Exchange rate regime and equity price responses, full sample: Table and test for equality

\begin{tabular}{lccccc}
\hline \hline & $\begin{array}{c}(1) \\
\text { Year o }\end{array}$ & $\begin{array}{c}(2) \\
\text { Year 1 }\end{array}$ & $\begin{array}{c}(3) \\
\text { Year 2 }\end{array}$ & $\begin{array}{c}(4) \\
\text { Year 3 }\end{array}$ & $\begin{array}{c}(5) \\
\text { Year 4 }\end{array}$ \\
\hline Pegs & $\begin{array}{c}-0.88 \\
(0.69)\end{array}$ & $\begin{array}{c}-2.91^{* * *} \\
(1.08)\end{array}$ & $\begin{array}{c}-2.22 \\
(1.52)\end{array}$ & $\begin{array}{c}-0.46 \\
(1.80)\end{array}$ & $\begin{array}{c}0.16 \\
(2.01)\end{array}$ \\
& 0.46 & -0.50 & 0.00 & -0.74 & $\begin{array}{c}-0.52 \\
\text { Floats }\end{array}$ \\
& $(0.40)$ & $(0.62)$ & $(0.88)$ & $(1.04)$ & $(1.16)$ \\
\hline Peg=Float (p-value) & $0.05^{*}$ & $0.02^{* *}$ & 0.14 & 0.87 & 0.73 \\
\hline$R^{2}$ & 0.57 & 0.57 & 0.44 & 0.37 & 0.31 \\
Observations & 810 & 810 & 810 & 810 & 810 \\
\hline \hline
\end{tabular}

Notes: Standard errors in parentheses. ${ }^{*} p<0.10,{ }^{* *} p<0.05,{ }^{* * *} p<0.01$.

Wald test for equality of peg and float responses.

Figure 9: Exchange rate regime and equity price responses, full sample: Figures
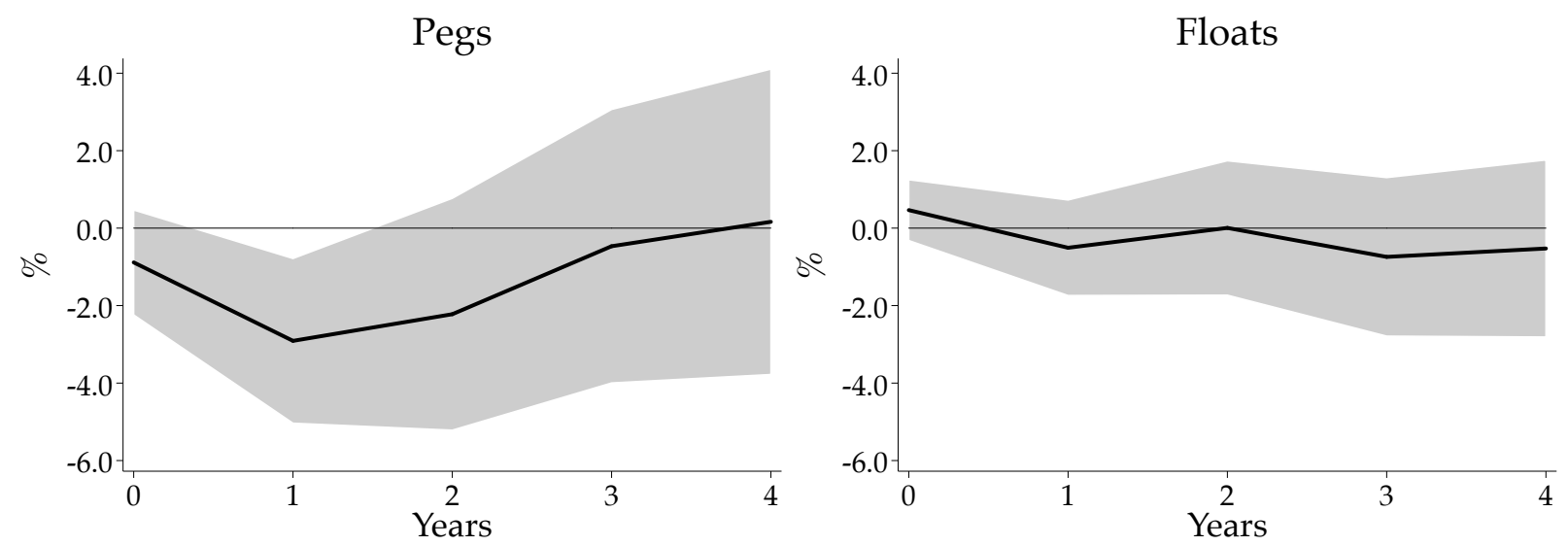

- Equity price 
Table 2: Exchange rate regime and equity price responses, post-1945: Table and test for equality

\begin{tabular}{lccccc}
\hline \hline & $\begin{array}{c}(1) \\
\text { Year o }\end{array}$ & $\begin{array}{c}(2) \\
\text { Year 1 }\end{array}$ & $\begin{array}{c}(3) \\
\text { Year 2 }\end{array}$ & $\begin{array}{c}(4) \\
\text { Year 3 }\end{array}$ & $\begin{array}{c}(5) \\
\text { Year 4 }\end{array}$ \\
\hline Pegs & -1.46 & $-8.36^{* *}$ & -6.94 & 3.05 & 6.63 \\
& $(2.23)$ & $(3.79)$ & $(5.55)$ & $(6.46)$ & $(7.17)$ \\
Floats & $0.94^{*}$ & $-3.10^{* * *}$ & -1.17 & 0.12 & -0.06 \\
& $(0.57)$ & $(0.97)$ & $(1.43)$ & $(1.66)$ & $(1.85)$ \\
\hline Peg=Float (p-value) & 0.27 & 0.15 & 0.29 & 0.64 & 0.34 \\
\hline$R^{2}$ & 0.74 & 0.70 & 0.55 & 0.52 & 0.48 \\
Observations & 577 & 577 & 577 & 577 & 577 \\
\hline \hline
\end{tabular}

Notes: Standard errors in parentheses. ${ }^{*} p<0.10,{ }^{* *} p<0.05,{ }^{* * *} p<0.01$.

Wald test for equality of peg and float responses.

Figure 10: Exchange rate regime and equity price responses, post-1945: Figures
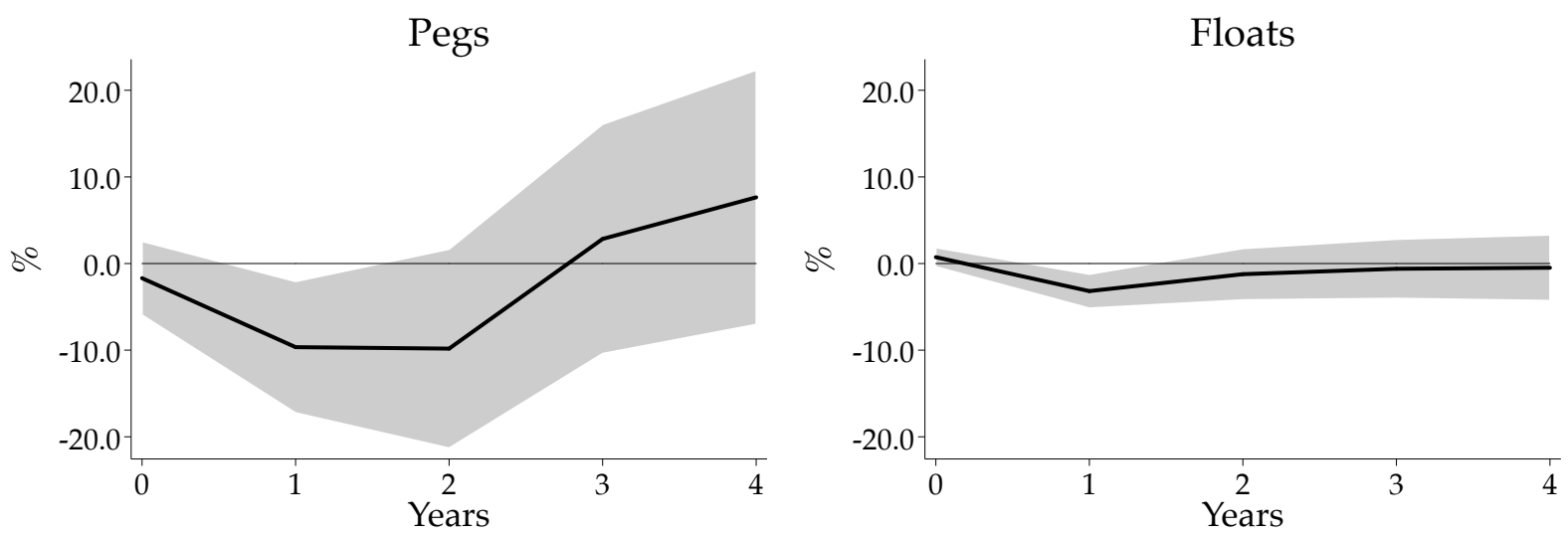

Equity price 
Table 3: Exchange rate regime and equity return premium responses, full sample: Table and test for equality

\begin{tabular}{lccccc}
\hline \hline & $(1)$ & $(2)$ & $(3)$ & $(4)$ & $(5)$ \\
& Year o & Year 1 & Year 2 & Year 3 & Year 4 \\
\hline Pegs & 0.00 & $3 \cdot 56^{* * *}$ & $2.91^{* *}$ & $3.19^{* *}$ & 0.84 \\
& $(1.23)$ & $(1.28)$ & $(1.28)$ & $(1.26)$ & $(1.31)$ \\
Floats & 0.00 & $1.90^{* *}$ & -0.28 & $2.74^{* * *}$ & $2.39^{* * *}$ \\
& $(0.71)$ & $(0.74)$ & $(0.74)$ & $(0.73)$ & $(0.75)$ \\
\hline Peg=Float (p-value) & 1.00 & 0.56 & $0.07^{*}$ & 0.71 & 0.06 \\
\hline$R^{2}$ & 0.43 & 0.46 & 0.45 & 0.48 & 0.43 \\
Observations & 810 & 810 & 810 & 810 & 810 \\
\hline \hline
\end{tabular}

Notes: Standard errors in parentheses. ${ }^{*} p<0.10,{ }^{* *} p<0.05,{ }^{* * *} p<0.01$.

Wald test for equality of peg and float responses (based on realized ERP).

Figure 11: Exchange rate regime and equity return premium responses, full sample: Figures
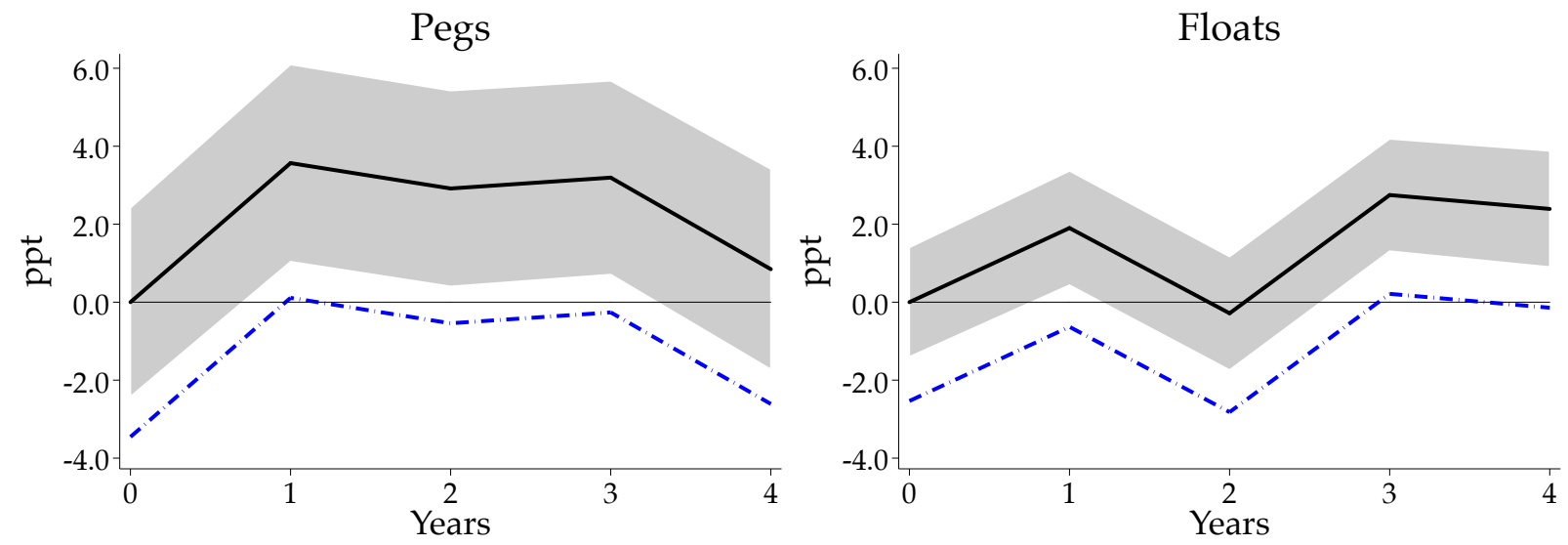

- Expected ERP --- Realized ERP 
Table 4: Exchange rate regime and equity return premium responses, post-1945: Table and test for equality

\begin{tabular}{lccccc}
\hline \hline & $\begin{array}{c}(1) \\
\text { Year o }\end{array}$ & $\begin{array}{c}(2) \\
\text { Year 1 }\end{array}$ & $\begin{array}{c}(3) \\
\text { Year 2 }\end{array}$ & $\begin{array}{c}(4) \\
\text { Year 3 }\end{array}$ & $\begin{array}{c}(5) \\
\text { Year } 4\end{array}$ \\
\hline Pegs & $\begin{array}{c}\text { O.00 } \\
(4.96)\end{array}$ & $\begin{array}{c}12.73^{* *} \\
(5.03)\end{array}$ & $\begin{array}{c}19.38^{* * *} \\
(5.06)\end{array}$ & $\begin{array}{c}12.85^{* *} \\
(4.93)\end{array}$ & $\begin{array}{c}4.84 \\
(4.87)\end{array}$ \\
Floats & O.00 & $\begin{array}{c}7.64^{* * *} \\
(1.30)\end{array}$ & $\begin{array}{c}4.83^{* * *} \\
(1.30)\end{array}$ & $\begin{array}{c}3.36^{* * *} \\
(1.27)\end{array}$ & $\begin{array}{c}3.29^{* * *} \\
(1.25)\end{array}$ \\
\hline Peg=Float (p-value) & $(1.28)$ & 0.72 & 0.12 & 0.58 & 0.26 \\
$R^{2}$ & 1.00 & 0.56 & 0.54 & 0.59 & 0.59 \\
\hline Observations & 0.52 & 577 & 577 & 577 & 577 \\
\hline \hline
\end{tabular}

Notes: Standard errors in parentheses. ${ }^{*} p<0.10,{ }^{* *} p<0.05,{ }^{* * *} p<0.01$.

Wald test for equality of peg and float responses (based on realized ERP).

Figure 12: Exchange rate regime and equity return premium responses, post-1945: Figures
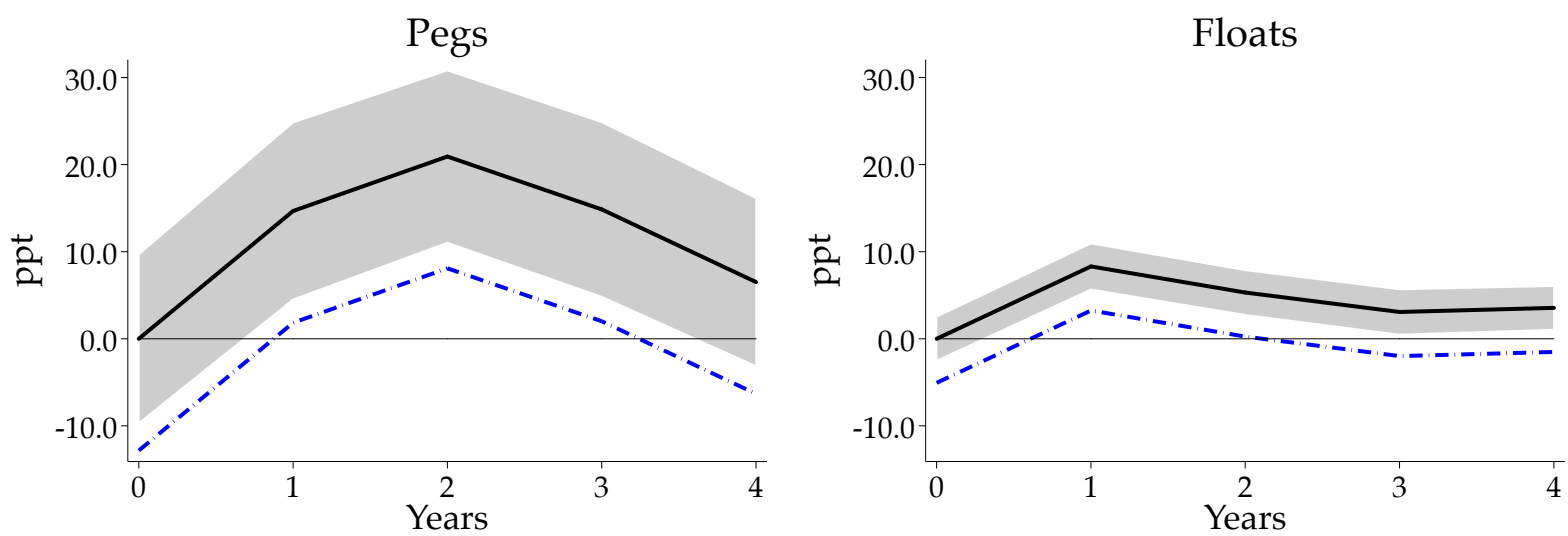

- Expected ERP --- Realized ERP 
We now turn to the post-WW2 subsample, as our previous results show that this is the period when risk premium spillovers were strongest. Figures 10 and 12 show the differential equity price- and ERP responses of pegs and floats to a +1ppt change in the U.S. rate. We find that for the post-WW2 sample the peg-float dichotomy is somewhat less stark. Floaters' equity prices and ERP now also show a response to center-country interest rate changes, but on a smaller scale. Pegs on average still exhibit a much stronger response, based on point estimates. However, the precision of these estimates is weak, Tables 2 and 4 show that a Wald test for equality of responses is unable to reject the null of equality at conventional confidence levels.

\section{MONETARY POLICY SHOCKS}

Although arguably exogenous from the perspective of a small economy, center country policy changes might not be unanticipated. To address such concerns, we confirm the above results using the high-frequency instruments (HFIs) for monetary policy changes discussed by Gürkaynak et al. (2005) and Gertler and Karadi (2015) in a local projection instrumental variable (LPIV) framework (see Jordà, Schularick, and Taylor, 2017b). These instruments measure changes in futures markets in a short time window around FOMC announcements and thereby capture the "surprise" component of a rate change.

The local projection instrumental variable approach to estimating impulse responses using high-frequency monetary policy instruments can be laid out as the following 2SLS setup. First the second-stage LP is specified as:

$$
\Delta_{h} y_{i, t+h}=\alpha_{i}^{h}+\sum_{k=1}^{5} \beta_{k}^{h} \Delta y_{i, t-k}+\sum_{k=0}^{5} \gamma_{k}^{h} \Delta \hat{R}_{i, t-k}^{c}+\sum_{k=0}^{5} \delta_{k}^{h} X_{i, t-k}+u_{i, t+h}, \quad h=1, \ldots, H,
$$

where $\hat{R}_{t}^{c}$ is the prediction from a first-stage regression of the effective federal funds rate $R^{c}$ on the high-frequency instruments and specified as:

$$
R_{t}^{c}=\theta_{0}+\theta_{1} F F 1_{t}+\theta_{3} F F 3_{t}+\theta_{6} E D 6_{t}+\theta_{9} E D 9+\theta_{1} 2 E D 12+\epsilon_{t}
$$

where $F F 1, F F 3, E D 6, E D 9$ and $E D 12$ are the high-frequency instruments. In the order specified, they are the unexpected changes in the Federal Funds futures of the current month, the 3-month ahead monthly Fed Funds futures and the 6-, 9- and 12-month ahead futures on 3-month Eurodollar deposits. 
Figure 13: Decomposing the global equity price response (high frequency instruments)
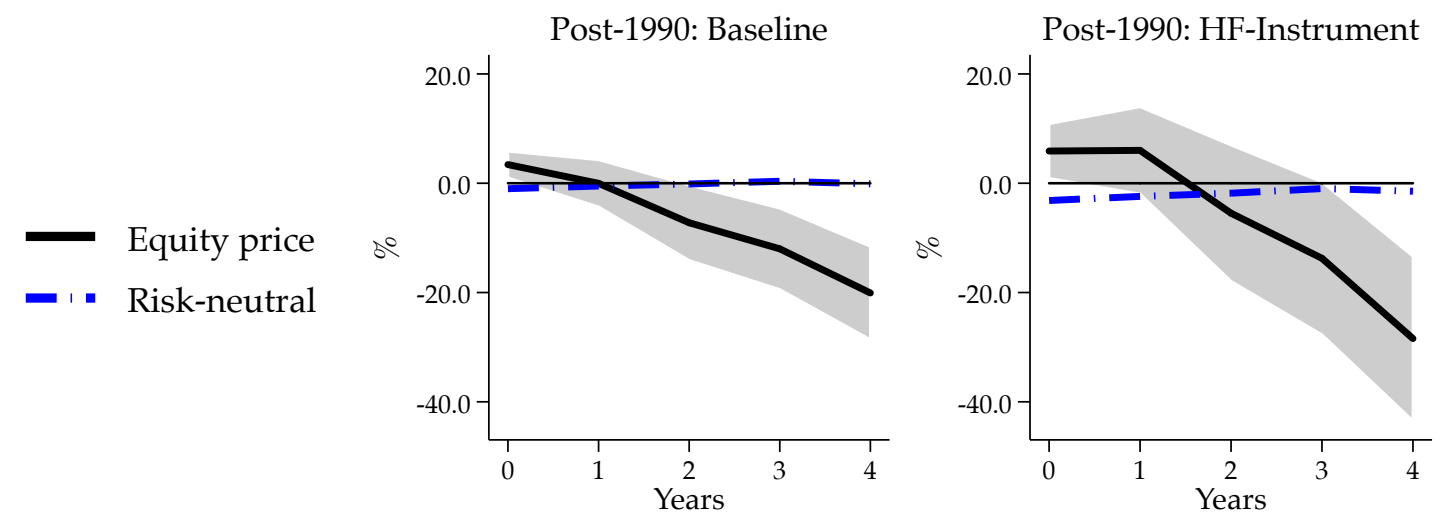

Dividend
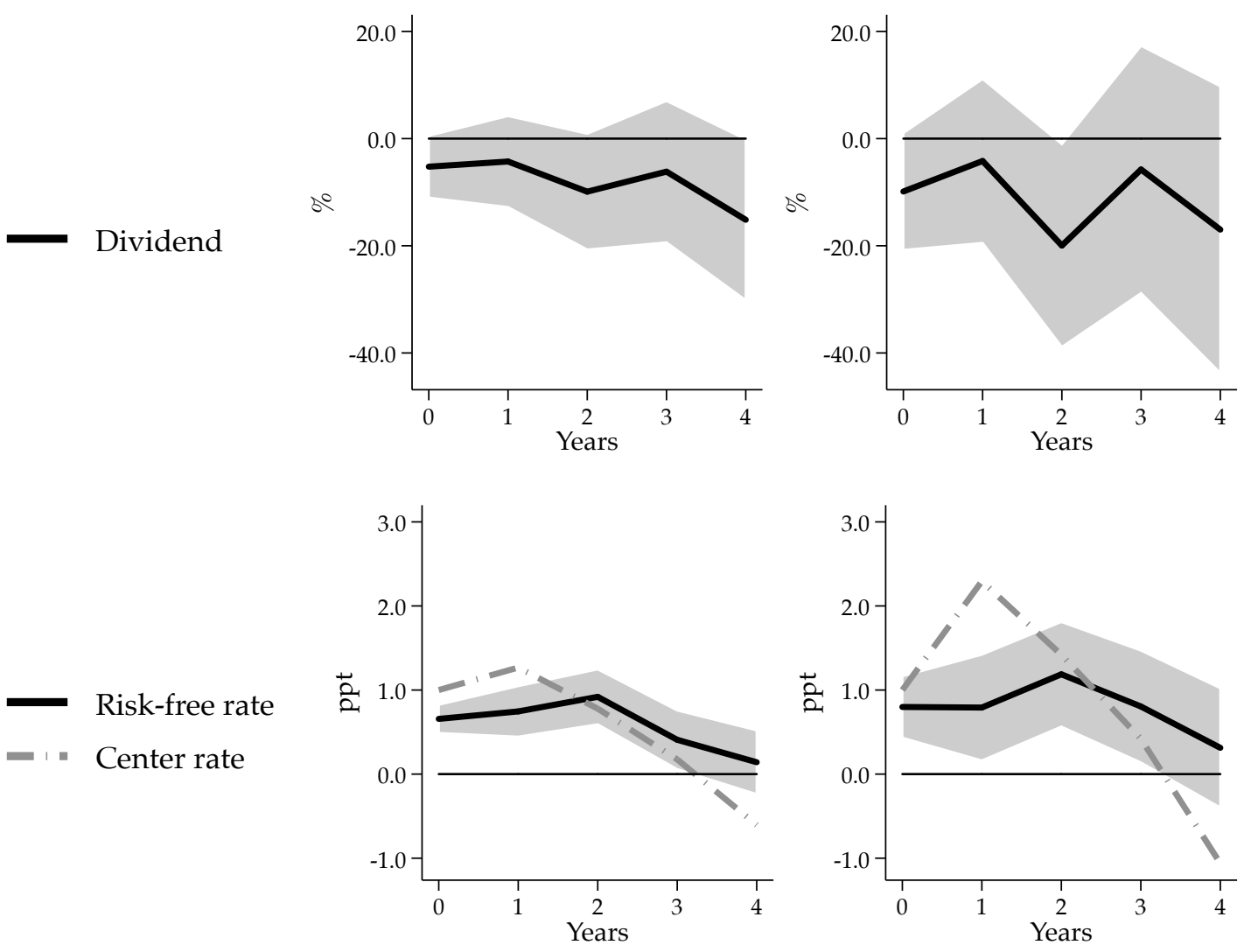

Notes: Cumulative impulse response functions to +1ppt increase in financial center interest rates. Riskneutral - risk neutral price $\left(Q^{R N}\right)$. Center rate - U.S. short-term risk-free rate own response. Confidence bands calculated on the basis of Driscoll-Kraay standard errors. Risk neutral price $\left(Q^{R N}\right)$ calculated according to equation 7 . 
Table 5: First stage regression results

\begin{tabular}{|c|c|c|c|c|c|}
\hline & (1) & (2) & (3) & (4) & (5) \\
\hline $\mathrm{FF}_{1}$ & $\begin{array}{c}1.88^{* * *} \\
(0.15)\end{array}$ & & $\begin{array}{c}1.22^{* * *} \\
(0.26)\end{array}$ & & $\begin{array}{c}1.46^{* * *} \\
(0.28)\end{array}$ \\
\hline $\mathrm{FF}_{3}$ & & $\begin{array}{c}2.13^{* * *} \\
(0.19)\end{array}$ & $\begin{array}{c}0.93^{* * *} \\
(0.32)\end{array}$ & & $\begin{array}{c}1.08^{* * *} \\
\left(0.3^{8}\right)\end{array}$ \\
\hline ED6 & & & & $\begin{array}{l}1.41^{*} \\
(0.80)\end{array}$ & $\begin{array}{l}-1.75^{*} \\
(0.89)\end{array}$ \\
\hline ED9 & & & & $\begin{array}{c}1.92 \\
(1.38)\end{array}$ & $\begin{array}{c}0.90 \\
(1.26)\end{array}$ \\
\hline ED12 & & & & $\begin{array}{c}-1.84^{* *} \\
(0.91)\end{array}$ & $\begin{array}{c}0.52 \\
(0.78)\end{array}$ \\
\hline$R^{2}$ & 0.35 & 0.31 & 0.36 & 0.17 & 0.38 \\
\hline Observations & 284 & 270 & 270 & 342 & 270 \\
\hline
\end{tabular}

Notes: Standard errors in parentheses. ${ }^{*} p<0.10,{ }^{* *} p<0.05,{ }^{* * *} p<0.01$.

Dependent variable: federal funds target rate change in ppts.

All variables in ppts changes; monthly observations.

We aggregate the monthly first stage predictions up to the annual level by taking the total sum of the predicted values over the twelve months within each year. Due to the shorter time span for which the high-frequency instruments are available this setup only allows us to compare the post-1990 impulse response functions.

The first stage results are displayed in Table 5. The high-frequency instruments are clearly relevant with $R^{2}$ statistics ranging from 0.17 to 0.38 , depending on which instruments are included. The following results are based on the specification including all HFIs (depicted in column 5).

The impulse responses we obtain for our baseline approach and the HFI approach are reassuringly similar in direction and magnitude, indicating that center-country interest rate changes can indeed be treated as largely exogenous for the rest of the world. Also note that the post-1990 responses are stronger than the post-1980 ones, indicating that the impact of U.S. monetary policy on the rest of the world has grown over time- similar to the results we presented above. 


\section{Discussion}

What explains the late 2oth century rise in international risk premium synchronization? The post-Bretton Woods synchronization of risk-premiums coincides with a rollback of capital controls and financial liberalization. These changes may have led to an increase in the international synchronization of risk premiums via the balance sheets of financial intermediaries (Ueda, 2012). Cross-country market integration of safe and risky assets should, by arbitrage, lead to an international equalization of the return on assets within the same risk-class, and hence an international equalization of risk premiums (Dedola and Lombardo, 2012). Kollmann et al. (2011) and Alpanda and Aysun (2014) present theoretical accounts where the equalization of global returns springs from the optimization problem of a global bank that aims to equalize its returns across regions. The observation that the post-Bretton Woods synchronization of risk premiums coincides with a period of capital account liberalization is consistent with such models. However, explanations based on financial openness beg the question of why risk premium comovement did not occur already in the first era of financial globalization before 1914 (Quinn and Voth, 2008). ${ }^{7}$

Behavioral theories of financial market behavior also offer explanations for investor overreaction. Behavioral theories attribute excess variation in asset prices to systematic mis-judgements in human psychology (Akerlof and Shiller, 2010; Kahneman and Tversky, 1979; Shiller, 2000) and to collective manias and panics (Kindleberger, 1978). The wedge that such "animal spirits" drive between fundamentals and asset valuations can help understand observed asset pricing puzzles (Bordalo et al., 2012; Gennaioli and Shleifer, 2010). If globally synchronized, behavioral forces could explain the international comovement of equity prices above and beyond what can be explained by fundamentals. For example, in a globalized world economy with global news flows, investors' sentiment can be synchronized by their exposure to a similar set of information.

Our empirical investigation does not provide conclusive evidence, but we note that the temporal pattern of international risk premium comovement again begs the question why behavioral forces did not induce extensive comovement in risk appetite in earlier

7The extent of international financial market integration in the late 19th and late 2oth centuries differs in several respects. While (net) cross-border capital flows and (net) foreign asset positions are comparable across both globalizations (Obstfeld and Taylor, 2004), financial globalization in the late 2oth century encompassed a wider range of financial assets than did its late 19th century precursor (Bordo et al., 1998). In particular late 19th century financial globalization was focused in industries with high tangible capital that were less plagued by information asymetries, such as railways, public bonds, mining and public utilities. Put differently, measured risk premiums might not be comparable across time. 
periods of financial globalization when international investors presumably were subject to the same cognitive constraints and similar information flows.

One explanation of this historical puzzle could be a key difference between the architecture of the late 19th and late 2oth century international monetary systems. Prior to 1914, global money aggregates were linked (to some degree) to global gold supply, which was fixed in the short run. As a consequence, global liquidity supply was quite inelastic in the short-run. On a regional level, it was zero-sum, and gold inflows and credit expansions in one region tended to be somewhat offset by gold outflows and credit contractions in other regions, as David Hume's famous theory proposed (Hume, 1742). The pre-1914 gold standard thus introduced a desynchronizing force into global finance that may have impeded the emergence of globally synchronized risk premiums. In contrast, in the post-Bretton Woods period, global finance has been built on a fiat money system that allows for a more elastic supply of liquidity, and no regional zero-sum effects. By and large, such a system is more likely to accommodate a globally synchronized expansion of liquidity supply and comovement in risk premiums. Such different elasticities of global liquidity in the pre-1914 and post-1970 financial globalizations could help to explain the temporal pattern of risk premium comovement we observe.

Another strand of the theoretical literature on global financial spillovers that could account for the observed temporal pattern of risk premium comovement relates to the form of international financial intermediation. What is new in the late 2oth century financial globalization is that international banks play a central role (Cassis et al., 2016, ch.11). The earlier financial globalization was not dominated by leveraged financial intermediaries. Instead, wealthy private individuals and mutual funds were the main vehicles for international capital flows (see Feis, 1964; Michie, 1986).

If banks hold foreign assets on their balance sheets and mark them to market, price changes can synchronize the risk appetite and the trading behavior of banks around the world (Adrian and Shin, 2009; Bruno and Shin, 2015; Miranda-Agrippino and Rey, 2015; Ward, 2018). For instance, if Federal Reserve policy affects U.S. equity prices, falling asset prices in the U.S. decrease (risk-weighted)-asset-capital ratios of U.S. as well as international banks which start to cut down their risk-taking in sync with U.S. banks. If no large risk-neutral player steps in to compensate for the lower risk taking of the leverage-constrained intermediaries, risk-spreads will increase. ${ }^{8}$

\footnotetext{
${ }^{8}$ For open economy models where international spillovers become stronger in the level of intermediary leverage see Devereux and Yetman (2010) and Ueda (2012).
} 
Schularick and Taylor (2012) show that late 2oth century banking is characterized by an explosion in bank credit and total bank assets, giving rise to a "financial hockey stick" pattern in the global credit-to-GDP ratio, that is reminiscient of the temporal pattern in international risk premium correlations. That this "financial hockey stick" pattern is closely related to important international business cycle moments has already been established by Jordà, Schularick, and Taylor (2016). For instance, investment and credit growth comovement increases in the bank credit-to-GDP ratio. The broad picture here is consistent with an important role of intermediary balance sheets for the amplification of international financial spillovers (Alpanda and Aysun, 2014; Dedola and Lombardo, 2012; Devereux and Yetman, 2010; Kollmann et al., 2011).

\section{CONClusions}

Based on our analysis we draw the following conclusions: First, the comovement in total loans, house prices, and equity prices has reached historical highs over the past few decades. In this sense it is possible to speak about a global financial cycle among developed economies. Second, the post-1980 increase in equity price comovement is particularly notable, because it has reached historically unprecedented levels and substantially exceeds the increase in the comovement in other real or financial variables. Third, the post-1980 synchronization of equity prices cannot be easily accounted for by the behavior of dividends or risk-free rates, but instead must be attributed to other factors. Here we have summarized such other factors under the label risk appetite, which includes factors, such as time variation in investor sentiment, or financial frictions.

What explains these evolving patterns? Monetary policy in center countries is one of the common drivers of global financial conditions, and thus one of the potential explanations for international financial comovement. Our analysis of the international spillover effects of financial center monetary policy leads us to the following conclusions: First, we find that the influence of U.S. monetary policy on international equity markets has increased over the 2oth century. Second, a large part of the increasing influence of U.S. monetary policy on international equity markets cannot be accounted for by its increasing influence on international dividends and risk-free rates, but instead must be attributed to the other factors summarized here as risk appetite.

Our analysis of financial comovement over the past 150 years adds a long-run perspective to the literature on international financial comovement. The aspects of the Global 
Financial Cycle we identify have been a pervasive feature throughout modern history, but right now their intensity has reached a peak. In contrast to the past, shocks to center-country monetary conditions and investor risk appetite seem to play the driving role in this outcome

\section{REFERENCES}

Adrian, Tobias, and Hyun Song Shin. 2009. Money, liquidity, and monetary policy. American Economic Review 99(2): 600-605.

Aikman, David, Andrew G. Haldane, and Benjamin D. Nelson. 2014. Curbing the credit cycle. Economic Journal 125(585): 1072-1109.

Akerlof, George A., and Robert J. Shiller. 2010. Animal spirits: How human psychology drives the economy, and why it matters for global capitalism. Princeton University Press.

Alpanda, Sami, and Uluc Aysun. 2014. International transmission of financial shocks in an estimated DSGE model. Journal of International Money and Finance 47: 21-55.

Ammer, John, and Jianping Mei. 1996. Measuring international economic linkages with stock market data. Journal of Finance 51(5): 1743-1763.

Bacchetta, Philippe, and Eric van Wincoop. 2013. Sudden spikes in global risk. Journal of International Economics 89(2): 511-521.

Backus, David K., Patrick J. Kehoe, and Finn E. Kydland. 1992. International real business cycles. Journal of Political Economy 100(4): 745-775.

Bekaert, Geert, Marie Hoerova, and Marco Lo Duca. 2013. Risk, uncertainty and monetary policy. Journal of Monetary Economics 6o(7): 771-788.

Bernanke, Ben S., and Kenneth N. Kuttner. 2005. What explains the stock market's reaction to Federal Reserve policy? Journal of Finance 6o(3): 1221-1257.

Bjørnland, Hilde C., and Kai Leitemo. 2009. Identifying the interdependence between US monetary policy and the stock market. Journal of Monetary Economics 56(2): 275-282.

Bordalo, Pedro, Nicola Gennaioli, and Andrei Shleifer. 2012. Salience theory of choice under risk. Quarterly Journal of Economics 127(3): 1243-1285.

Bordo, Michael D., Barry Eichengreen, and Jongwoo Kim. 1998. Was there really an earlier period of international financial integration comparable to today? NBER Working Paper 6738.

Bordo, Michael D., and Thomas Helbling. 2003. Have national business cycles become more synchronized? NBER Working Paper 10130.

Bruno, Valentina, and Hyun Song Shin. 2014. Cross-border banking and global liquidity. Review of Economic Studies 82(2): 535-564.

Bruno, Valentina, and Hyun Song Shin. 2015. Capital flows and the risk-taking channel of monetary policy. Journal of Monetary Economics 71: 119-132.

Cagliarini, Adam, and Fiona Price. 2017. Exploring the link between the macroeconmic and financial cycles. RBA Working Paper.

Campbell, John Y. 1991. A variance decomposition for stock returns. Economic Journal 101(405): 157-179.

Campbell, John Y., and Robert J. Shiller. 1988. The dividend-price ratio and expectations of future dividends and discount factors. Review of Financial Studies 1(3): 195-228. 
Canova, Fabio. 2005. The transmission of US shocks to Latin America. Journal of Applied Econometrics 20(2): 229-251.

Cassis, Youssef, Richard S. Grossman, and Catherine R. Schenk. 2016. The Oxford Handbook of Banking and Financial History. Oxford University Press.

Castelnuovo, Efrem, and Salvatore Nisticò. 2010. Stock market conditions and monetary policy in a DSGE model for the US. Journal of Economic Dynamics and Control 34(9): 1700-1731.

Cerutti, Eugenio, Stijn Claessens, and Lev Ratnovski. 2014. Global liquidity and drivers of cross-border bank flows. IMF Working Paper 14/69.

Cetorelli, Nicola, and Linda S. Goldberg. 2012. Banking globalization and monetary transmission. Journal of Finance 67(5): 1811-1843.

Chadha, Jagjit S., Lucio Sarno, and Giorgio Valente. 2004. Monetary policy rules, asset prices, and exchange rates. IMF Economic Review 51(3): 529-552.

Chiţu, Livia, Barry Eichengreen, and Arnaud Mehl. 2014. When did the Dollar overtake Sterling as the leading international currency? Evidence from the bond markets. Journal of Development Economics 111: 225-245.

Claessens, Stijn, M. Ayhan Kose, and Marco E. Terrones. 2011. Financial Cycles: What? How? When? NBER International Seminar on Macroeconomics 7(1): 303-344.

Cochrane, John H. 2005. Asset pricing: Revised edition. Princeton University Press.

Dedola, Luca, and Giovanni Lombardo. 2012. Financial frictions, financial integration and the international propagation of shocks. Economic Policy 27(70): 319-359.

Devereux, Michael B., and James Yetman. 2010. Leverage constraints and the international transmission of shocks. Journal of Money, Credit and Banking 42(s1): 71-105.

Drehmann, Mathias, Claudio Borio, and Kostas Tsatsaronis. 2012. Characterising the financial cycle: Don't lose sight of the medium term! BIS Working Papers 380.

Driscoll, John C., and Aart C. Kraay. 1998. Consistent covariance matrix estimation with spatially dependent panel data. Review of Economics and Statistics 8o(4): 549-56o.

Dumas, Bernard, Campbell R. Harvey, and Pierre Ruiz. 2003. Are correlations of stock returns justified by subsequent changes in national outputs? Journal of International Money and Finance 22(6): 777-811.

Ehrmann, Michael, Marcel Fratzscher, and Roberto Rigobon. 2011. Stocks, bonds, money markets and exchange rates: Measuring international financial transmission. Journal of Applied Econometrics 26(6): 948-974.

Engsted, Tom, and Carsten Tanggaard. 2004. The comovement of US and UK stock markets. European Financial Management 10(4): 593-607.

Feis, Herbert. 1964. Europe, the world's banker, 1870-1914: An account of European foreign investment and the connection of world finance with diplomacy before the war. Augustus M. Kelley.

Forbes, Kristin J., and Roberto Rigobon. 2002. No contagion, only interdependence: Measuring stock market comovements. The Journal of Finance 57(5): 2223-2261.

Fostel, Ana, and John Geanakoplos. 2008. Leverage cycles and the anxious economy. The American Economic Review 98(4): 1211-1244.

Furlanetto, Francesco. 2011. Does monetary policy react to asset prices? Some international evidence. International Journal of Central Banking 7(3): 91-111.

Galí, Jordi, and Luca Gambetti. 2015. The effects of monetary policy on stock market bubbles: Some evidence. American Economic Journal: Macroeconomics 7(1): 233-257.

Gennaioli, Nicola, and Andrei Shleifer. 2010. What comes to mind. Quarterly Journal of Economics 
125(4): 1399-1433.

Gertler, Mark, and Peter Karadi. 2015. Monetary policy surprises, credit costs, and economic activity. American Economic Journal: Macroeconomics 7(1): 44-76.

Gürkaynak, Refet S., Brian Sack, and Eric T. Swanson. 2005. Do actions speak louder than words? The response of asset prices to monetary policy actions and statements. International Journal of Central Banking 1(1): 55-93.

Hamilton, James D. forthcoming. Why you should never use the Hodrick-Prescott filter. Review of Economics and Statistics.

Harding, Don, and Adrian Pagan. 2002. Dissecting the cycle: A methodological investigation. Journal of Monetary Economics 49(2): 365-381.

Hume, David. 1742. Of the balance of trade. In Essays: Moral, Political, and Literary, edited by Miller, Eugene F., chapter II, essay V. Liberty Fund Inc., 1987 edition.

Ilzetzki, Ethan, Carmen M. Reinhart, and Kenneth S. Rogoff. 2017. Exchange rate arrangements entering the 21st century: Which anchor will hold? NBER Working Paper 23134.

Jordà, Òscar. 2005. Estimation and inference of impulse responses by local projections. American Economic Review 95(1): 161-182.

Jordà, Òscar, Katharina Knoll, Dmitry Kuvshinov, Moritz Schularick, and Alan M. Taylor. $2017 a$. The rate of return on everything, 1870-2015. NBER Working Paper 24112.

Jordà, Òscar, Moritz Schularick, and Alan M. Taylor. 2015. Betting the house. Journal of International Economics 96: 2-18.

Jordà, Òscar, Moritz Schularick, and Alan M. Taylor. 2016. Macrofinancial history and the new business cycle facts. NBER Macroeconomics Annual 31(1): 213-263.

Jordà, Òscar, Moritz Schularick, and Alan M. Taylor. 2017b. The effects of quasi-random monetary experiments. NBER Working Paper 23074.

Kahneman, Daniel, and Amos Tversky. 1979. Prospect theory: An analysis of decision under risk. Econometrica 47(2): 263-291.

Kapetanios, George. 2008. A bootstrap procedure for panel data sets with many cross-sectional units. Econometrics Journal 11(2): 377-395.

Kim, Soyoung. 2001. International transmission of US monetary policy shocks: Evidence from VAR's. Journal of Monetary Economics 48(2): 339-372.

Kindleberger, Charles P. 1978. Manias, panics, and crashes: A history of financial crises. New York: Wiley, 2005 edition.

Klein, Michael W., and Jay C. Shambaugh. 2008. The dynamics of exchange rate regimes: Fixes, floats, and flips. Journal of International Economics 75(1): 70-92.

Klein, Michael W., and Jay C. Shambaugh. 2015. Rounding the corners of the policy trilemma: Sources of monetary policy autonomy. American Economic Journal: Macroeconomics 7(4): 33-66.

Kollmann, Robert, Zeno Enders, and Gernot J. Müller. 2011. Global banking and international business cycles. European Economic Review 55(3): 407-426.

Kuvshinov, Dmitry. 2018. Time-varying risk, sentiment and the macroeconomy. Unpublished manuscript.

Meller, Barbara, and Norbert Metiu. 2017. The synchronization of credit cycles. Journal of Banking and Finance 82: 98-111.

Michie, Ranald C. 1986. The London and New York stock exchanges, 1850-1914. Journal of Economic History 46(1): 171-187.

Miranda-Agrippino, Silvia, and Hélene Rey. 2015. World asset markets and the global financial 
cycle. NBER Working Paper 21722.

Obstfeld, Maurice. 2014. Trilemmas and trade-offs: Living with financial globalization. BIS Working Paper 480.

Obstfeld, Maurice, Jay C. Shambaugh, and Alan M. Taylor. 2004. Monetary sovereignty, exchange rates, and capital controls: The trilemma in the interwar period. IMF Staff Papers 51(1): 75-108.

Obstfeld, Maurice, Jay C. Shambaugh, and Alan M. Taylor. 2005. The trilemma in history: Tradeoffs among exchange rates, monetary policies, and capital mobility. Review of Economics and Statistics 87(3): 423-438.

Obstfeld, Maurice, Jay C. Shambaugh, and Alan M. Taylor. 2010. Financial stability, the trilemma, and international reserves. American Economic Journal: Macroeconomics 2(2): 57-94.

Obstfeld, Maurice, and Alan M. Taylor. 2004. Global capital markets: Integration, crisis, and growth. Cambridge University Press.

Quinn, Dennis P., and Hans-Joachim Voth. 2008. A century of global equity market correlations. American Economic Review 98(2): 535-540.

Rigobon, Roberto, and Brian Sack. 2004. The impact of monetary policy on asset prices. Journal of Monetary Economics 51(8): 1553-1575.

Schularick, Moritz, and Alan M. Taylor. 2012. Credit booms gone bust: Monetary policy, leverage cycles and financial crises, 1870-2008. American Economic Review 102(2): 1029-1061.

Schüler, Yves Stephan, Paul Hiebert, and Tuomas A. Peltonen. 2015. Characterising the financial cycle: A multivariate and time-varying approach. ECB Working Paper 1846.

Shambaugh, Jay C. 2004. The effect of fixed exchange rates on monetary policy. Quarterly Journal of Economics 119(1): 301-352.

Shiller, Robert J. 1981a. Do stock prices move too much to be justified by subsequent changes in dividends? American Economic Review 71(3): 421-436.

Shiller, Robert J. 1981b. The use of volatility measures in assessing market efficiency. Journal of Finance 36(2): 291-304.

Shiller, Robert J. 2000. Irrational exuberance. Wiley Online Library.

Shin, Hyun Song. 2012. Global banking glut and loan risk premium. IMF Economic Review 6o(2): 155-192.

Ueda, Kozo. 2012. Banking globalization and international business cycles: Cross-border chained credit contracts and financial accelerators. Journal of International Economics 86(1): 1-16.

Ward, Felix. 2018. Global risk taking, exchange rates, and monetary policy. Working paper. 
Appendix A: Global averages

Figure A.1: Global average cycles
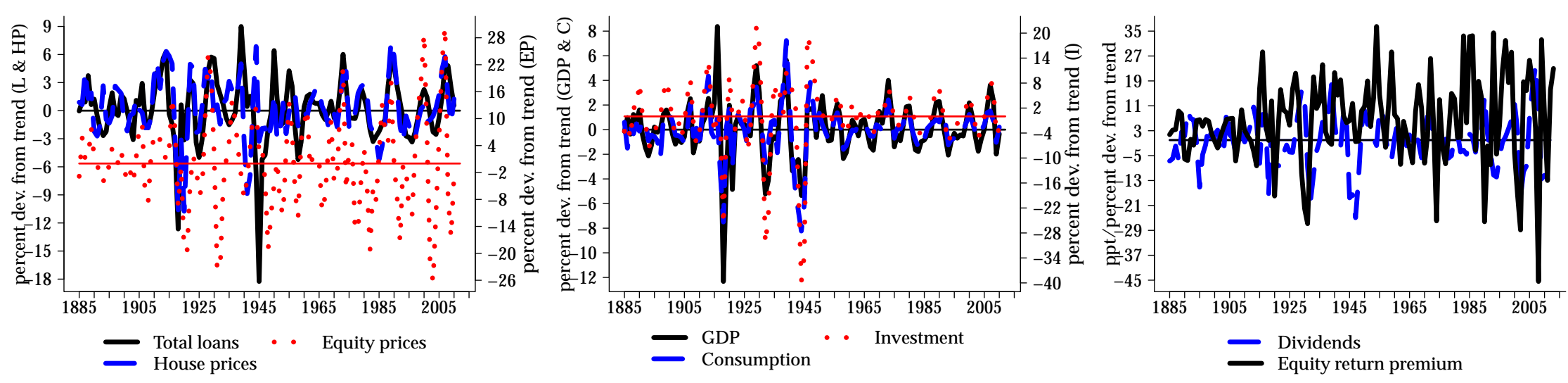

w
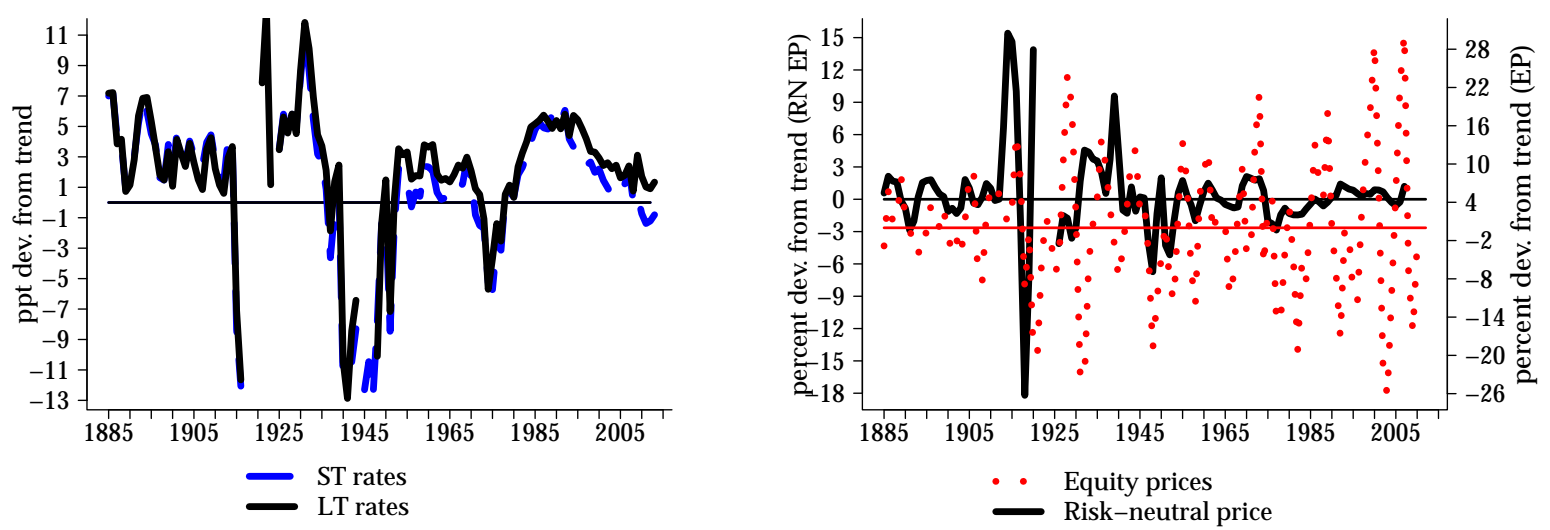

Notes: Global means. All series were detrended with a Baxter-King filter isolating cycles in the 2 to 32 -year period range. The equity return premium series and interest rate series are depicted in levels. Outliers have been dropped from the graph in order to simplify the graphical exposition. 
Figure A.2: Global average cycles (2-8 year cycles)
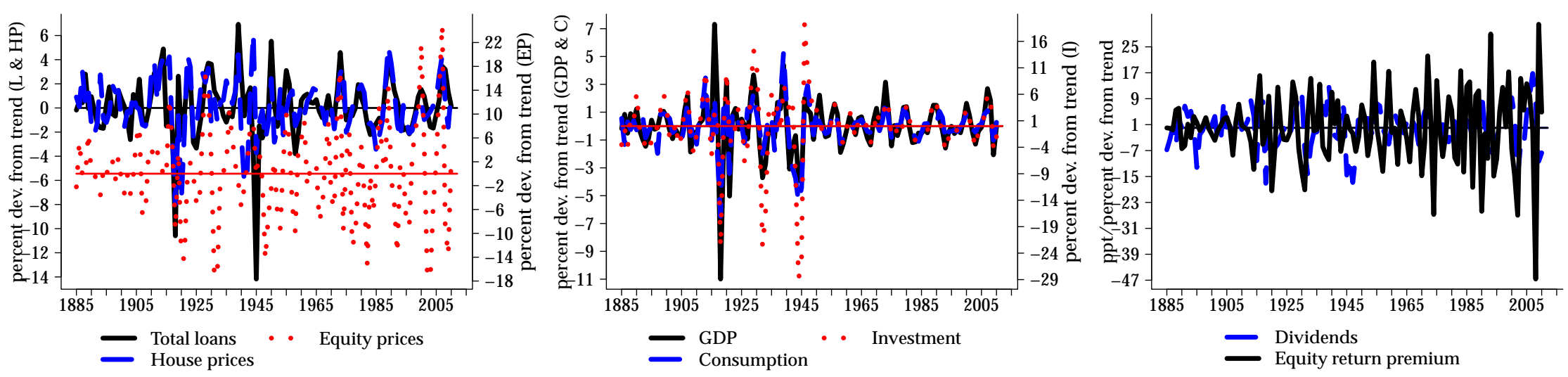

w
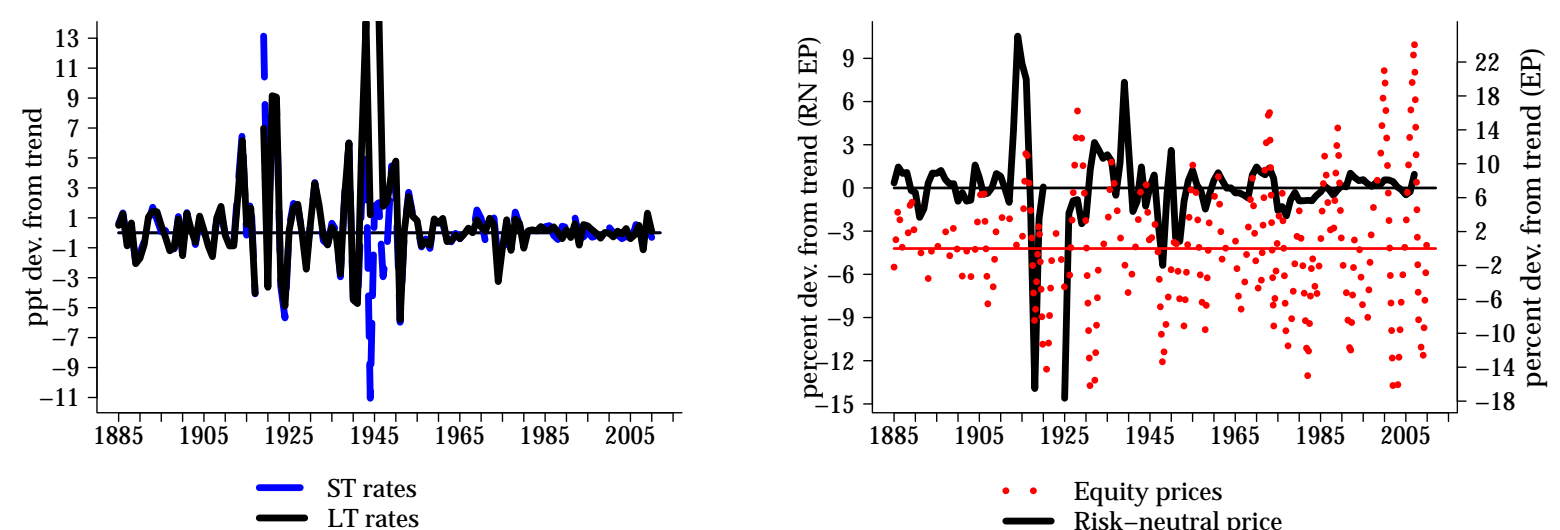

Notes: Global means. All series were detrended with a Baxter-King filter isolating cycles in the 2 to 8 -year period range. Outliers have been dropped from the graph in order to simplify the graphical exposition. 
Figure A.3: Global average cycles (Hamilton filter)
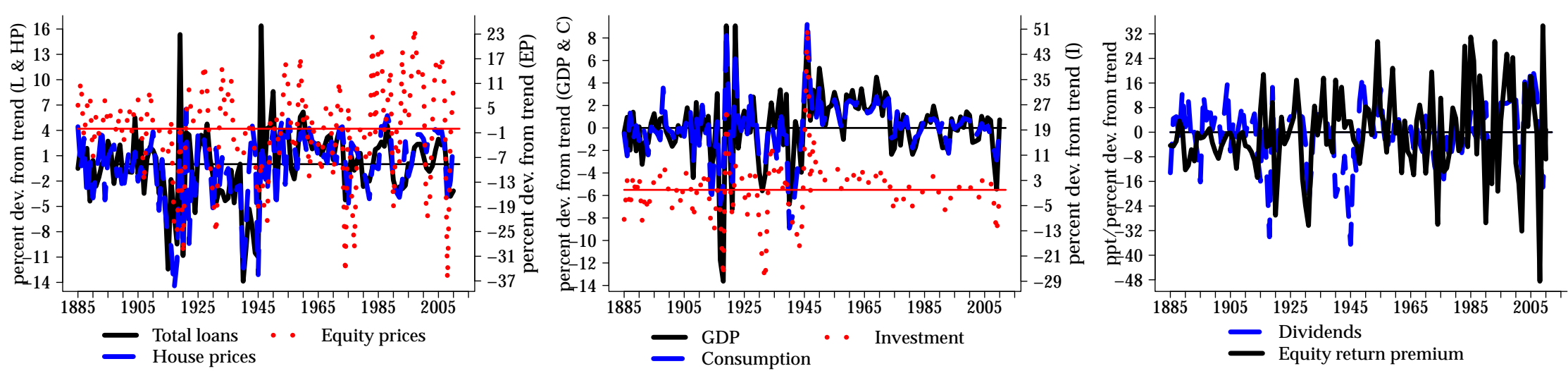

$\stackrel{w}{v}$
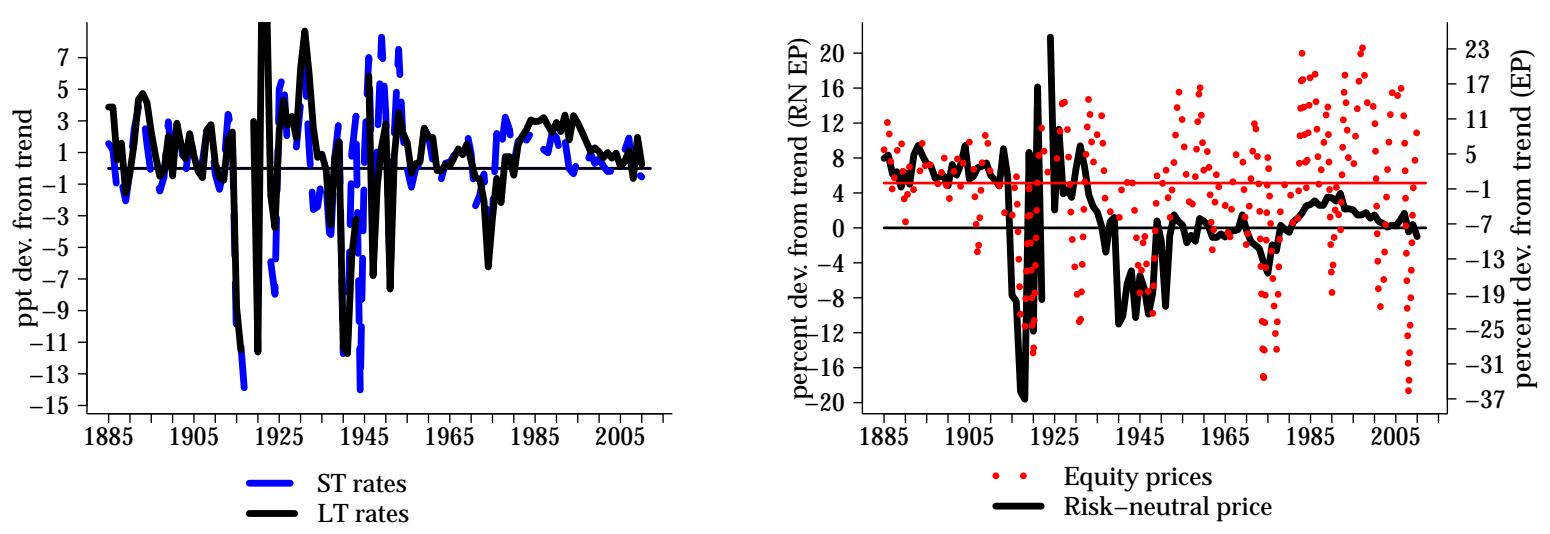

Notes: Global means. All series were detrended with the Hamilton filter, using lags one to four. Outliers have been dropped from the graph in order to simplify the graphical exposition. 


\section{Appendix B: Average bilateral correlations}

Figure A.4: Average bilateral correlation (2-8 year cycles)
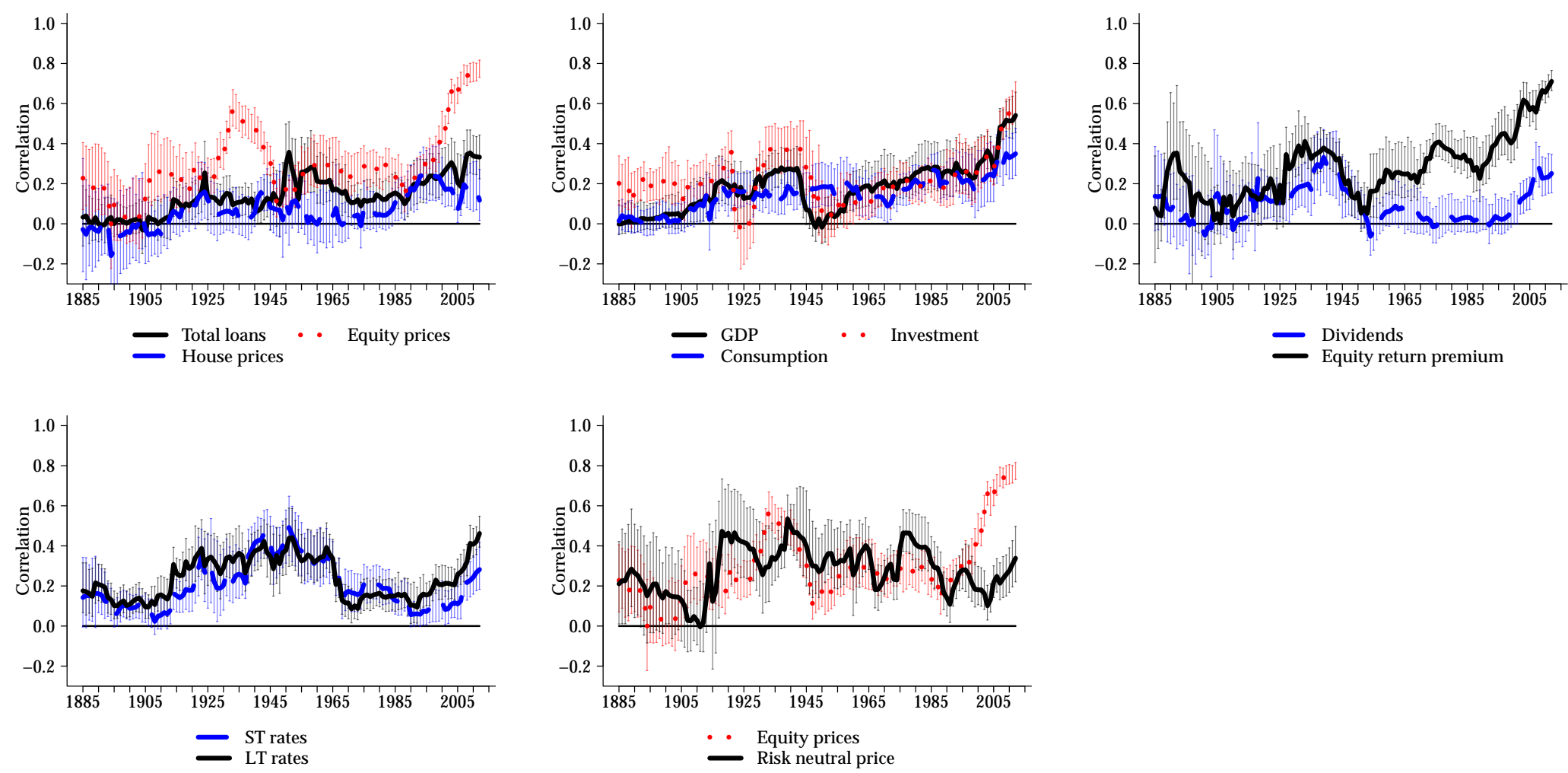

Notes: Spearman rank correlation coefficients based on 15-year rolling windows. 2 to 8-year period Baxter-King detrended series. Bars - 95\% cross-sectionally block-bootstrapped confidence bands. 
Figure A.5: GDP-weighted average bilateral correlation (2-32 year cycles)
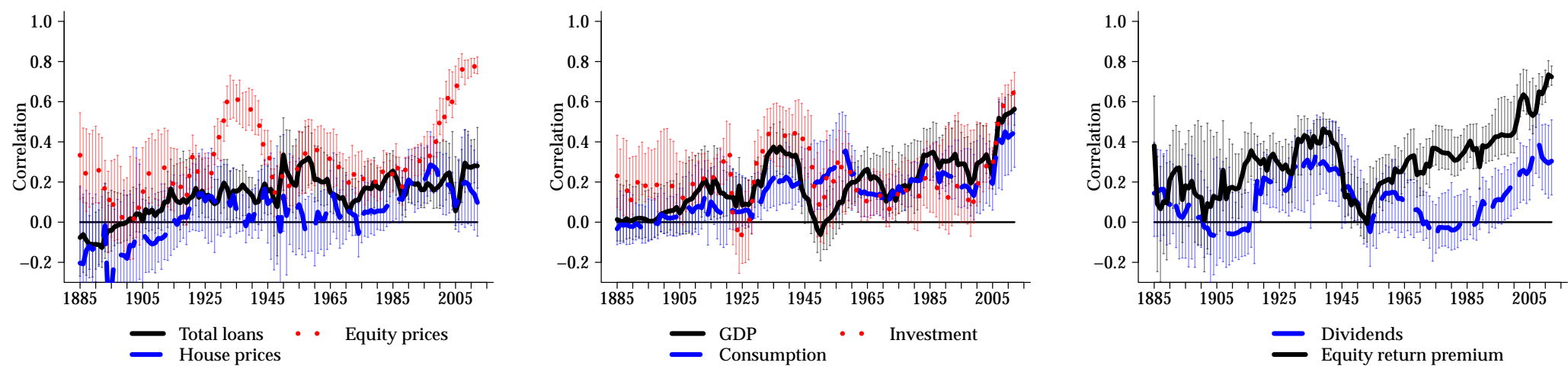

$\omega_{\sigma}^{\omega}$
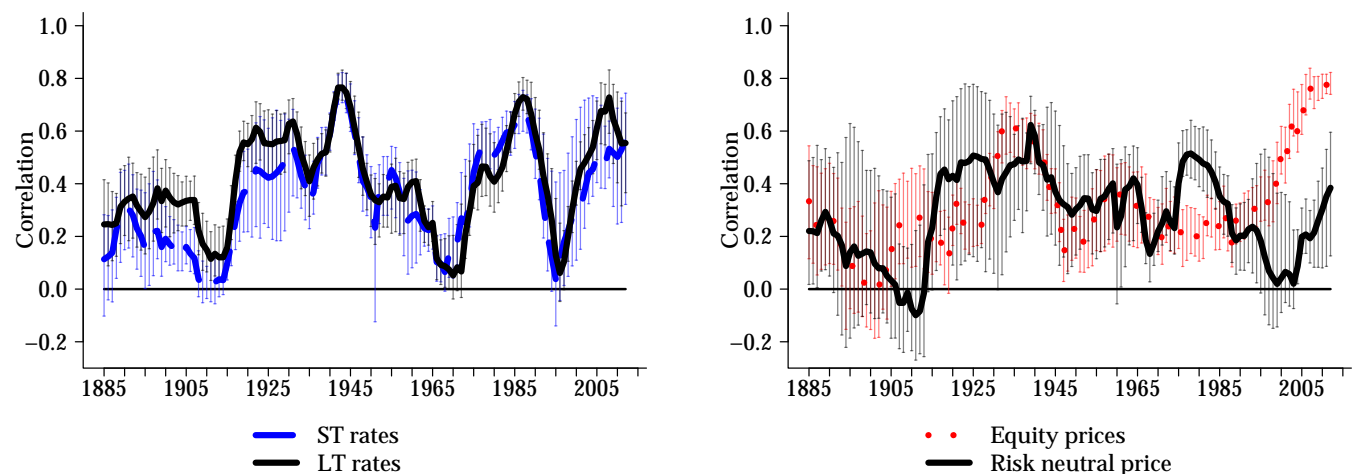

Notes: Spearman rank correlation coefficients based on 15-year rolling windows. 2 to 32-year period Baxter-King detrended series. Bars - 95\% cross-sectionally block-bootstrapped confidence bands. 
Figure A.6: Average bilateral correlation (Hamilton filter)
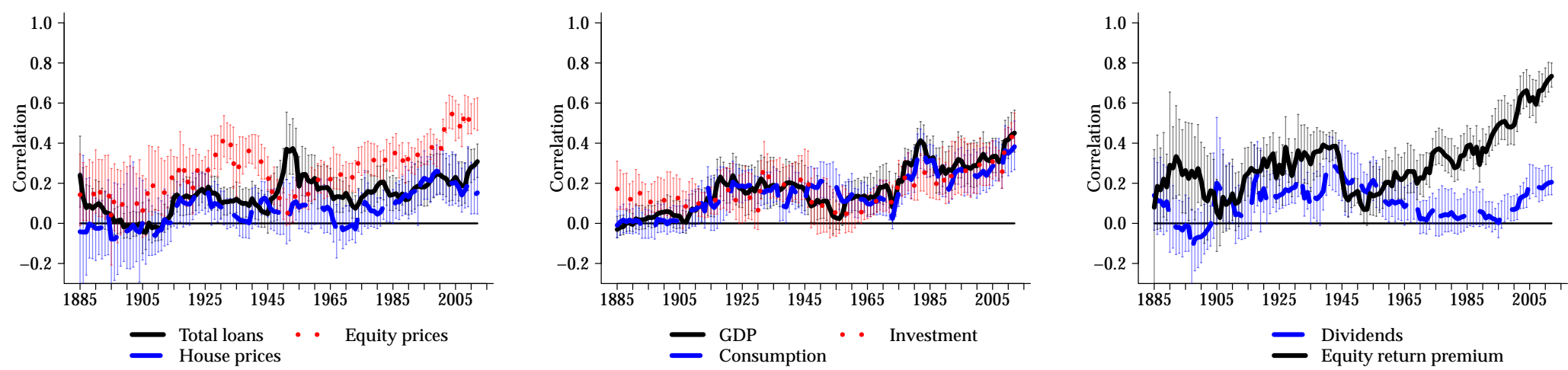

$\frac{1}{0}$
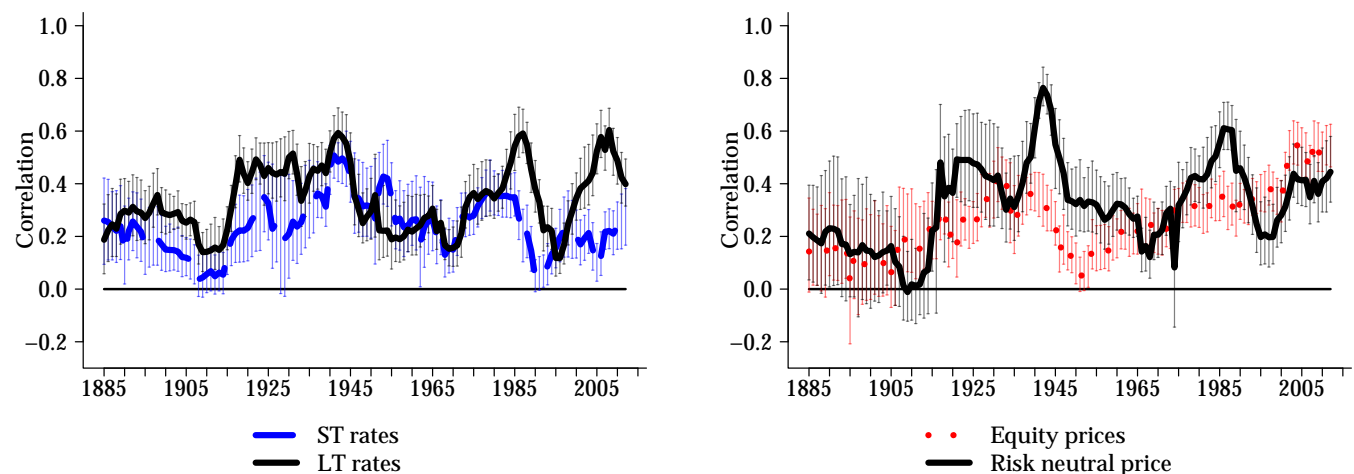

Notes: Spearman rank correlation coefficients based on 15-year rolling windows. Hamilton filter detrended series (using lags one to four). Bars $-95 \%$ cross-sectionally block-bootstrapped confidence bands. 
Figure A.7: Average bilateral correlation (annual growth rates and first differences)
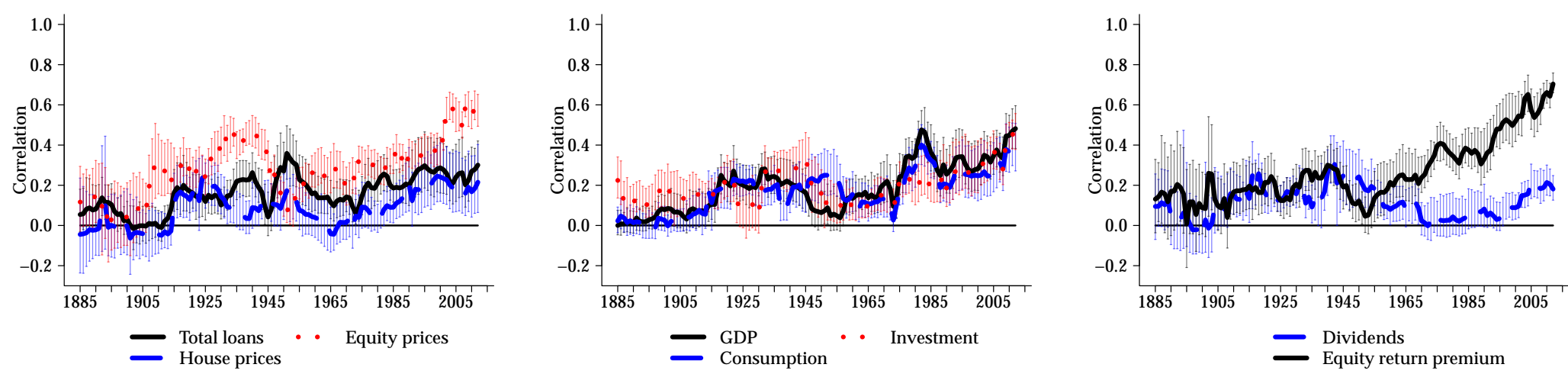

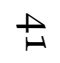
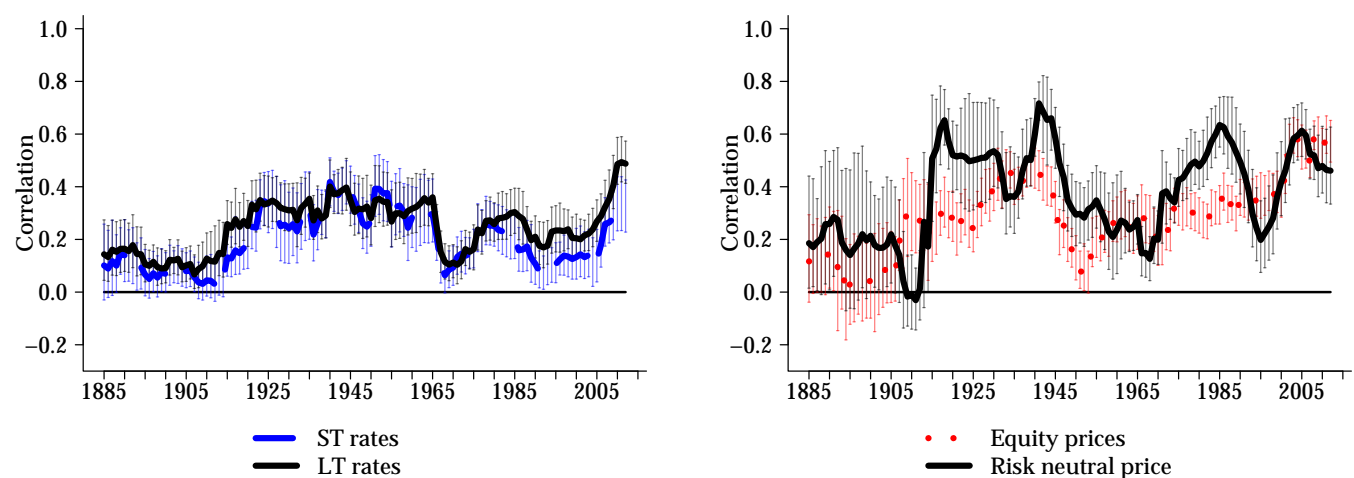

Notes: Spearman rank correlation coefficients based on 15-year rolling windows. First differences (for the equity return premium and interest rates) and growth rates for all other variables. Bars $-95 \%$ cross-sectionally block-bootstrapped confidence bands. 
Figure A.8: Average bilateral correlation (Pearson correlation coefficient)
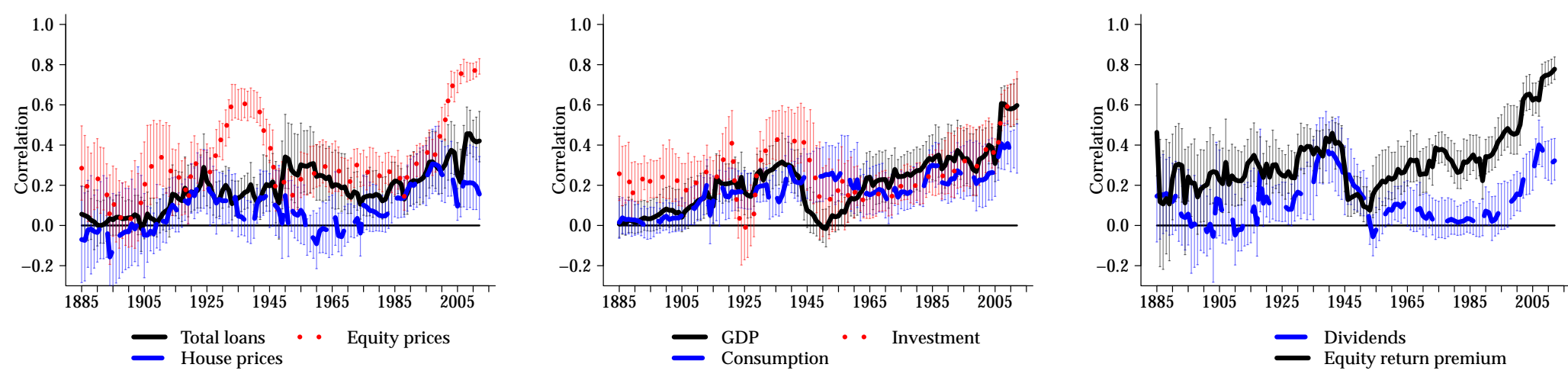

N
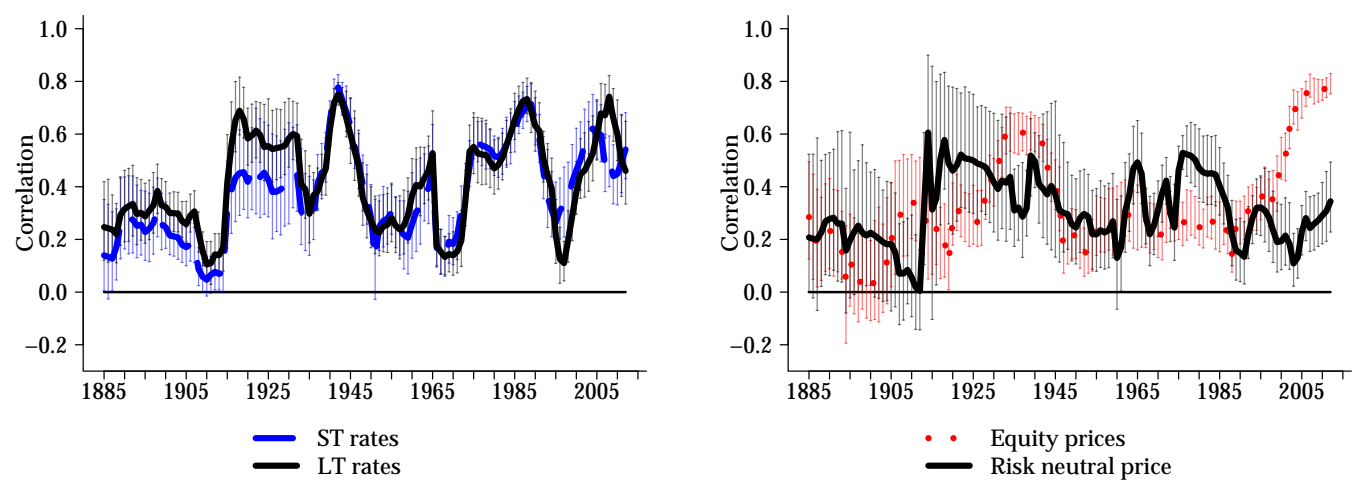

Notes: Pearson correlation coefficients based on 15-year rolling windows. 2 to 32-year period Baxter-King detrended series. Bars $-95 \%$ cross-sectionally block-bootstrapped confidence bands. 
Figure A.9: Average bilateral correlation (USA)
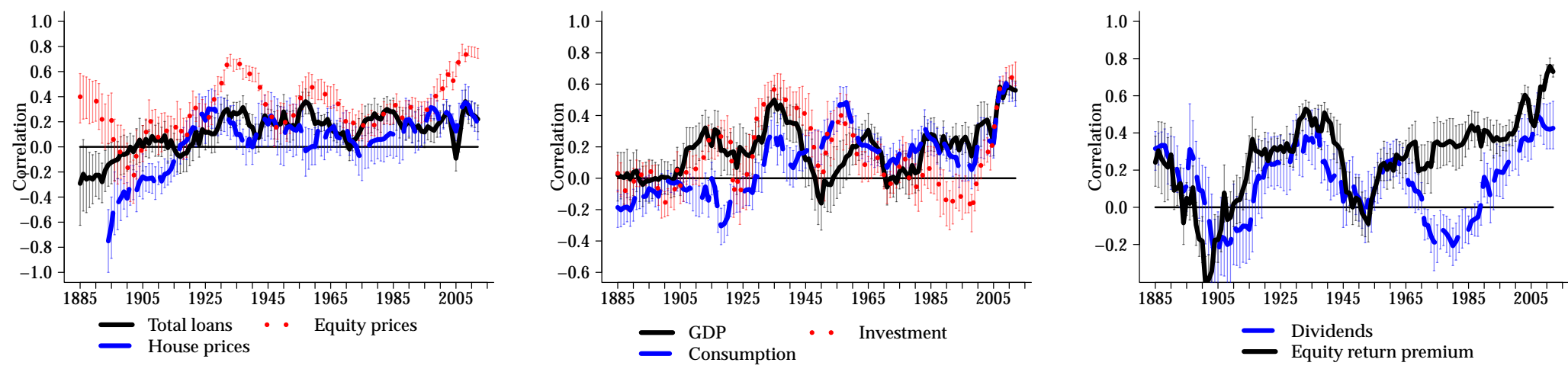

$\stackrel{\leftrightarrow}{\omega}$
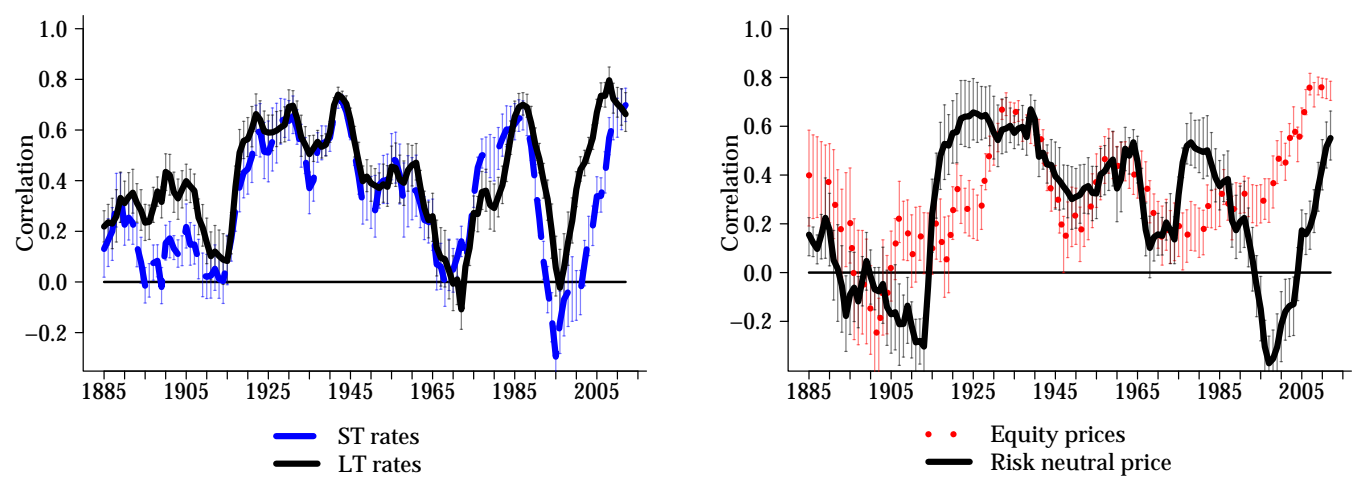

Notes: Spearman rank correlation coefficients based on 15-year rolling windows. 2 to 32-year period Baxter-King detrended series. Bars - 95\% cross-sectionally block-bootstrapped confidence bands. Average of all bilateral U.S. country-pair correlations. 
Figure A.10: Average bilateral concordance
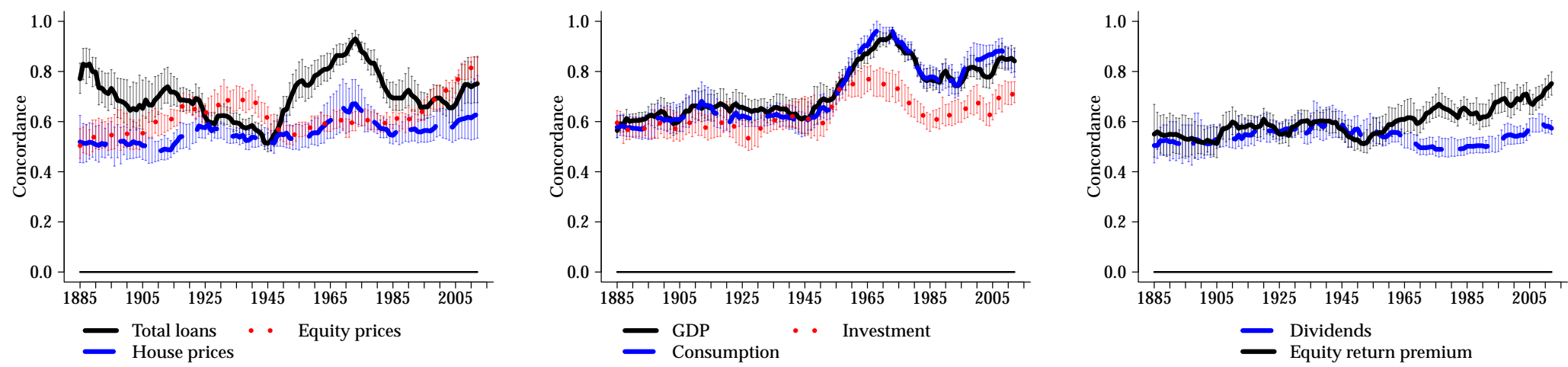

$\stackrel{+}{+}$
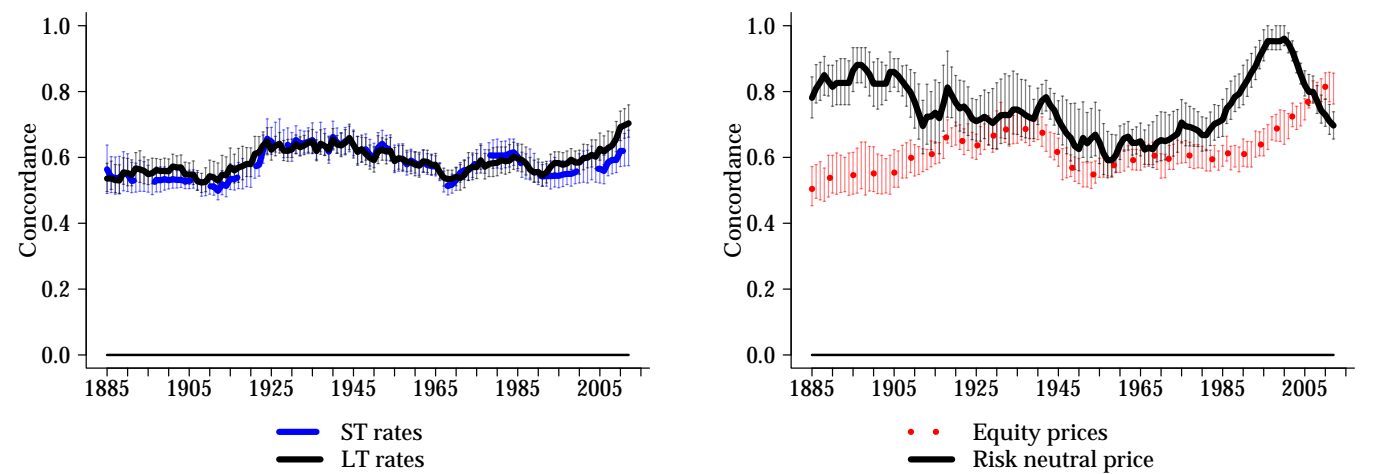

Notes: Concordance based on 15-year rolling windows. Peaks defined as highest values in $+/-2$ year window. Minimum phase length 2 years. Minimum cycle length 4 years. Bars $-95 \%$ cross-sectionally block-bootstrapped confidence bands. 
Figure A.11: Regional correlations: Europe
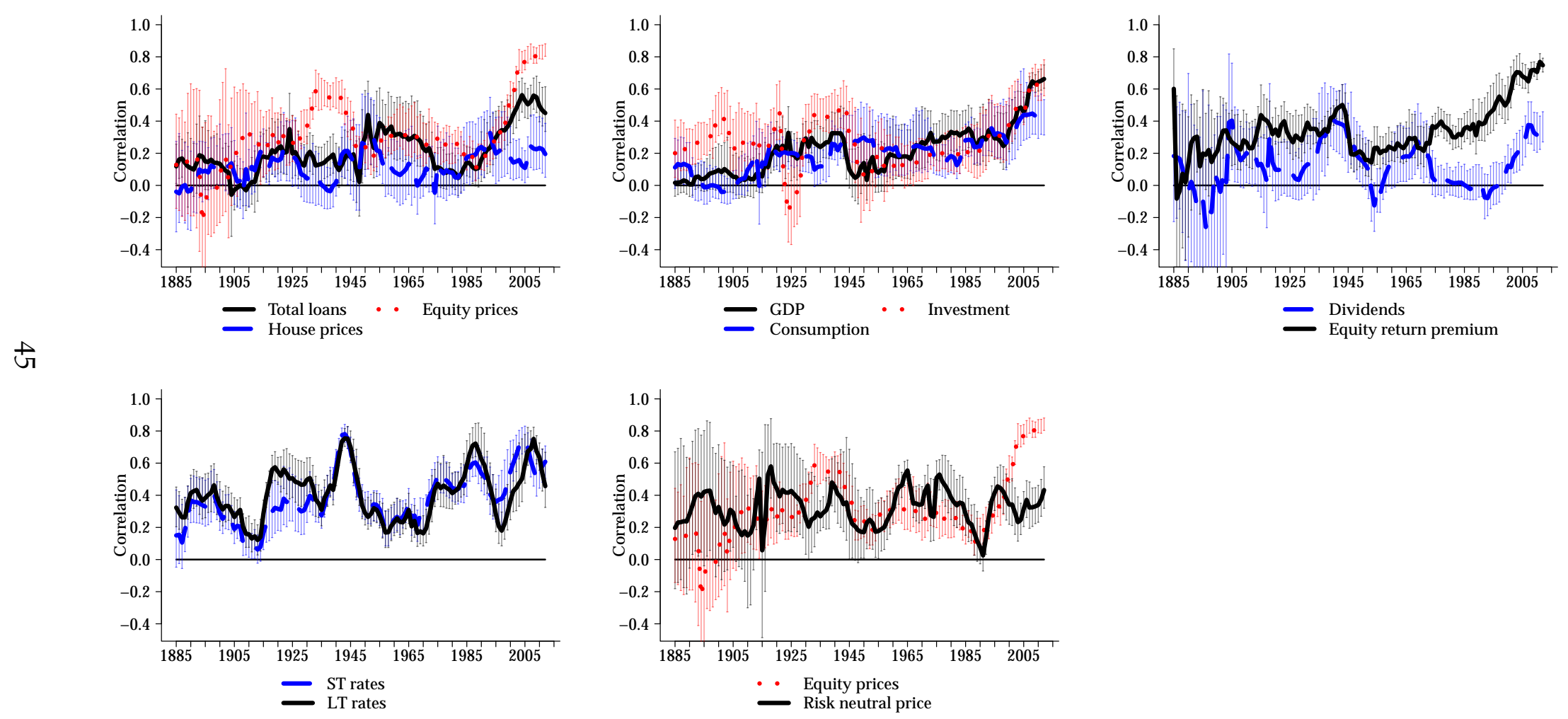

Notes: Spearman rank correlation coefficients based on 15-year rolling windows. All series were detrended with a Baxter-King filter isolating cycles in the 2 to 32 -year period range. Bars $-95 \%$ cross-sectionally block-bootstrapped confidence bands. 
Figure A.12: Regional correlations: Euro area
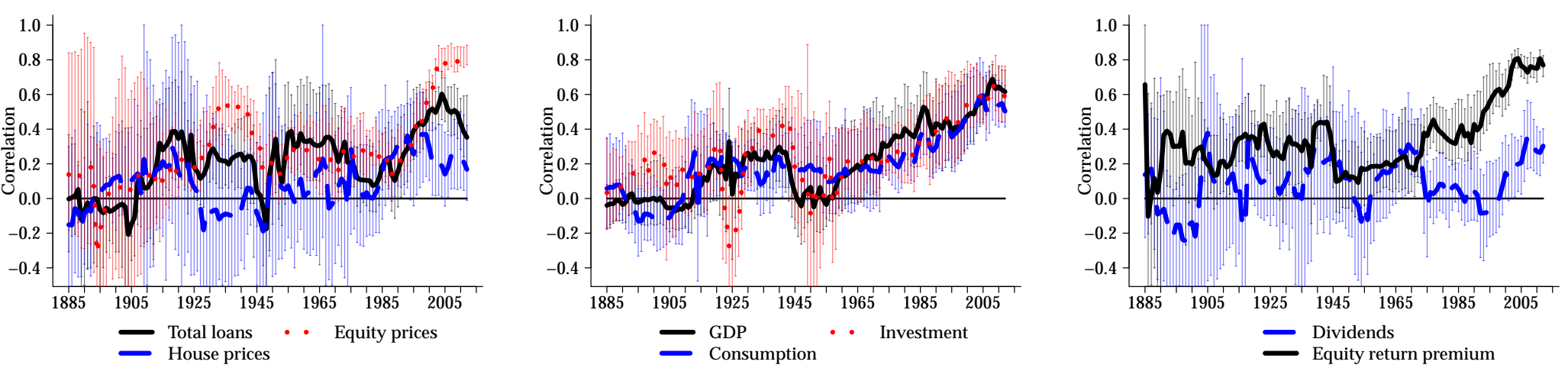

a
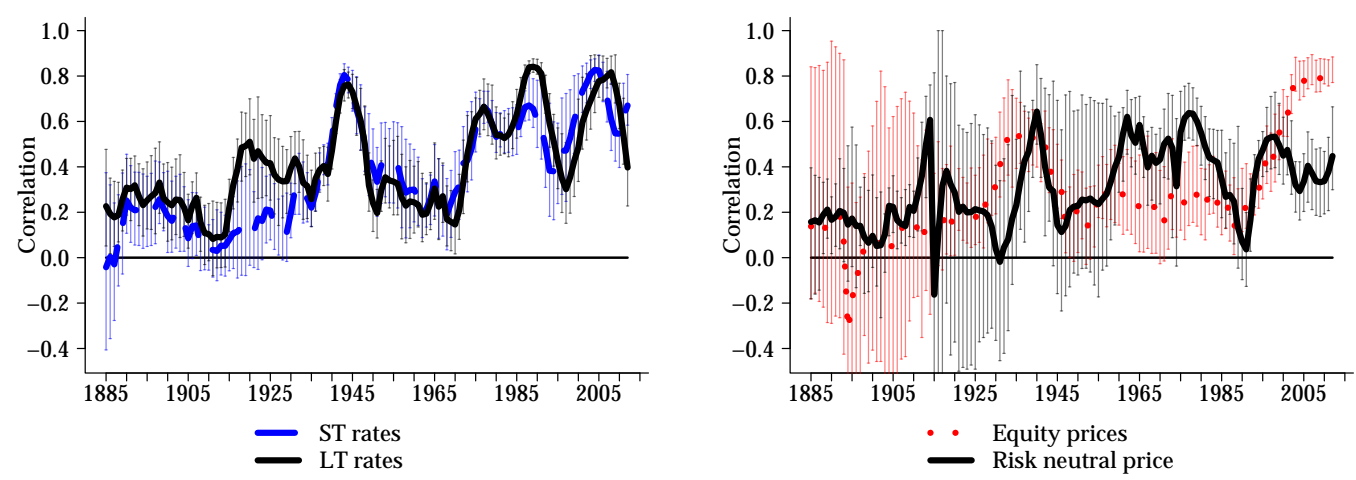

Notes: Spearman rank correlation coefficients based on 15-year rolling windows. All series were detrended with a Baxter-King filter isolating cycles in the 2 to 32 -year period range. Bars $-95 \%$ cross-sectionally block-bootstrapped confidence bands. 
Figure A.13: Regional correlations: Scandinavia
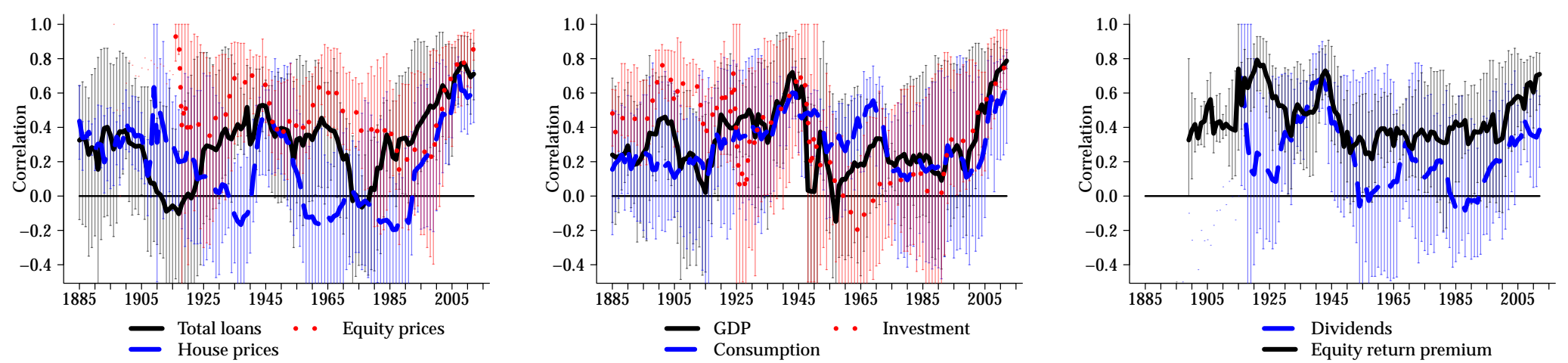

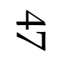
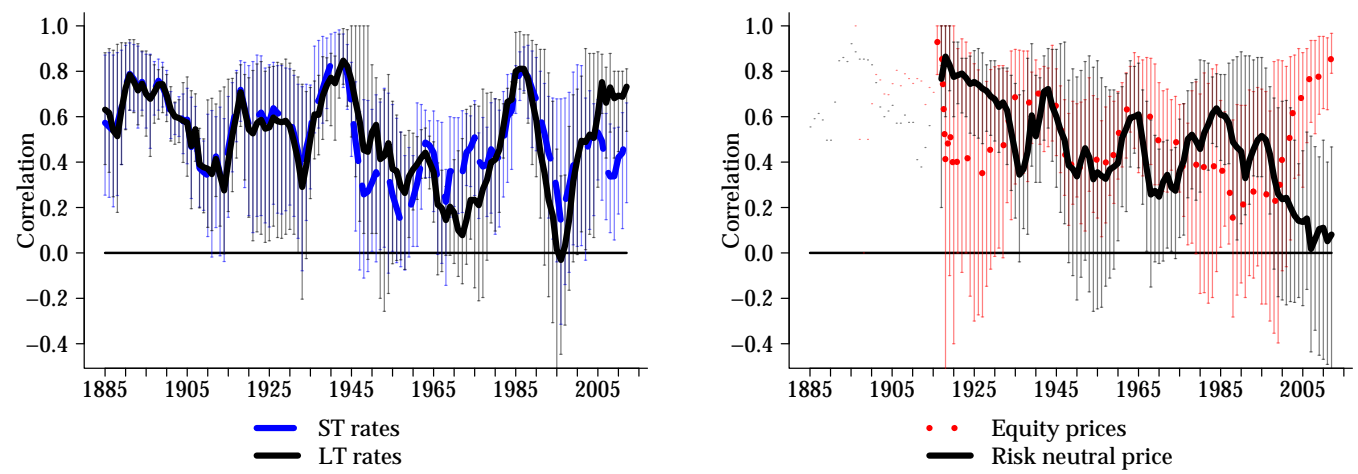

Notes: Scandinavia: Denmark, Finland, Norway, and Sweden. Spearman rank correlation coefficients based on 15-year rolling windows. All series were detrended with a Baxter-King filter isolating cycles in the 2 to 32 -year period range. Bars $-95 \%$ cross-sectionally blockbootstrapped confidence bands. 
Figure A.14: Regional correlations: Pacific
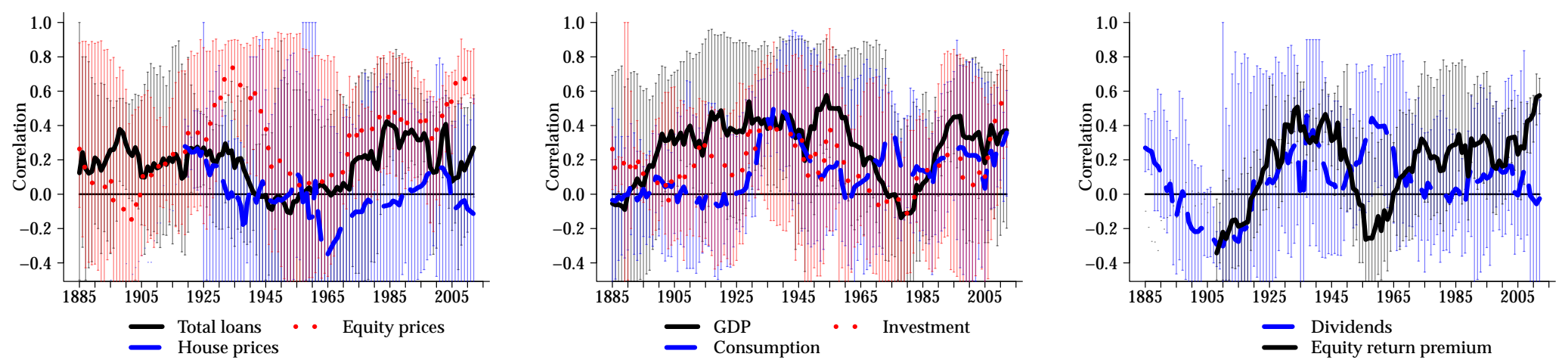

$\frac{\infty}{\infty}$
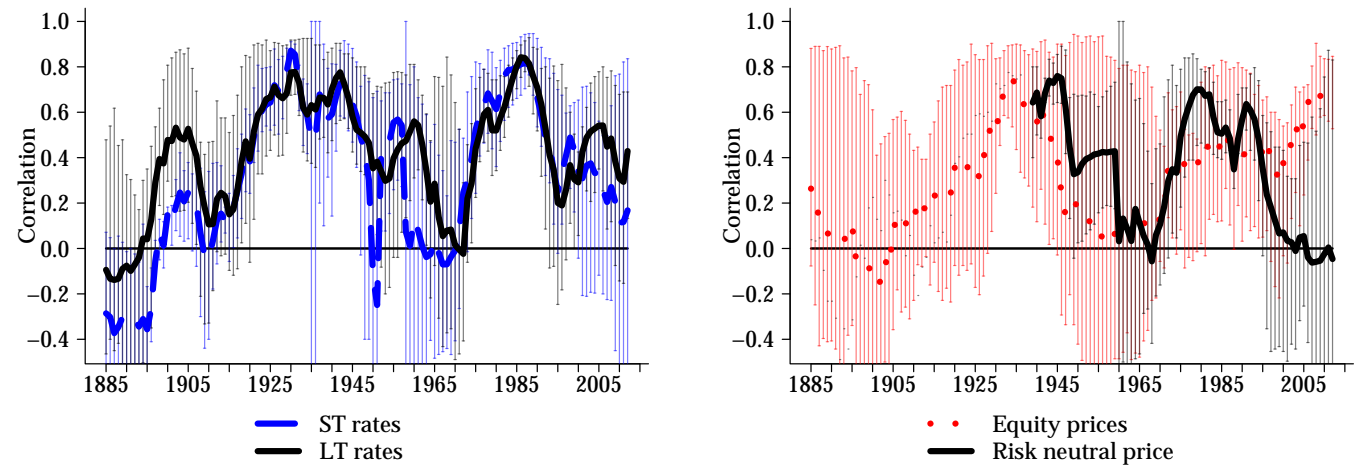

Notes: Pacific region: Australia, Canada, Japan, and U.S.A. Spearman rank correlation coefficients based on 15-year rolling windows. All series were detrended with a Baxter-King filter isolating cycles in the 2 to 32 -year period range. Bars $-95 \%$ cross-sectionally block-bootstrapped confidence bands. 


\section{APPENDIX C: EQUITY RETURN PREMIUM COVARIANCE DECOMPOSITION}

This section decomposes equity return premiums through a vector autoregression (VAR) decomposition in the spirit of Campbell (1991). The advantage of such decompositions over the comovement analyses presented so far is that they explicitly model investor expectations, and thus do not require the equalization of ex-ante expected values with expost realized ones. A recent example for such a decomposition based on the long-run data we use is Kuvshinov (2018). In particular, we build on the two-country decomposition suggested by Ammer and Mei (1996). This approach attributes unexpected fluctuations in the current equity return premium of country $i\left(\tilde{e}_{t+1}^{i}\right)$ to news about future discounted dividends, risk-free rates and equity return premiums.

\section{The return premium model}

Starting from the log gross equity return definition

$$
h_{t+1}=\log \left(P_{t+1}+D_{t+1}\right)-\log \left(P_{t}\right)
$$

where $P$ denotes the equity price and $D$ the dividend paid. A first order Taylor approximation yields

$$
h_{t+1} \approx \delta_{t}-\rho \delta_{t+1}+\Delta d_{t+1}+k,
$$

where $\Delta d$ denotes the first difference of the log of the dividend payment $D, \delta$ is the dividend-price ratio, $\rho$ is a (discount) factor smaller than 1 and $k$ is a linearization constant (see Campbell and Shiller, 1988). Solving (16) forward ${ }^{9}$, taking expectations and plugging the resulting expectation equations for $\delta_{t}$ and $\delta_{t+1}$ back into (16) results in the following expression for the unexpected change in the log real return on equity:

$$
h_{t+1}-E_{t} h_{t+1}=\left(E_{t+1}-E_{t}\right)\left[\sum_{k=0}^{\infty} \rho^{k} \Delta d_{t+1+k}-\sum_{k=1}^{\infty} \rho^{k} h_{t+1+k}\right],
$$

where $E_{t}$ is an expectation operator denoting expectations formed on the basis of information available through $t$. Put in terms of equity return premiums $e_{t+1}:=h_{t+1}-r_{t+1}$,

\footnotetext{
${ }^{9}$ Note the assumption of the transversality condition $\lim _{k \rightarrow \infty} \rho^{k} \delta_{t+k}=0$, as well as $E_{t} \delta_{t}=\delta_{t}$.
} 
where $r$ denotes the log real interest rate, equation (17) can be rewritten as

$$
e_{t+1}-E_{t} e_{t+1}=\left(E_{t+1}-E_{t}\right)\left[\sum_{k=0}^{\infty} \rho^{k} \Delta d_{t+1+k}-\sum_{k=0}^{\infty} \rho^{k} r_{t+1+k}-\sum_{k=1}^{\infty} \rho^{k} e_{t+1+k}\right] \text {, }
$$

or more compactly, for any country $i$

$$
\tilde{e}_{t+1}^{i}=\tilde{e}_{d, t+1}^{i}-\tilde{e}_{r, t+1}^{i}-\tilde{e}_{e, t+1}^{i}
$$

The general intuition behind equation 19 is that innovations in the equity return premium of country $i$ can be decomposed into news about the discounted sum of future dividend streams, news about the discounted sum of future risk-free real interest rates, and news about the discounted sum of future equity return premiums. Thus, if the equity return premium increases, this is either due to news about higher future dividends, lower future risk-free rates or lower future return premiums.

Consider the same decomposition for another country $j$. In order to render real equity returns in $j$ comparable to those in $i$ it is necessary to introduce a real exchange rate term $\tilde{e}_{q, t+1}$ :

$$
\tilde{e}_{t+1}^{j}=\tilde{e}_{d, t+1}^{j}-\tilde{e}_{r, t+1}^{j}-\tilde{e}_{e, t+1}^{j}-\tilde{e}_{q, t+1^{\prime}}^{j}
$$

where $\tilde{e}_{q, t+1}=\left(E_{t+1}-E_{t}\right) \sum_{k=0}^{\infty} \rho^{k} q_{t+1+k}$ denotes news about the sum of future discounted log real exchange rates. ${ }^{10}$

We are interested in characterizing the comovement of return premiums in countries $i$ and $j, \tilde{e}_{t+1}^{i}$ and $\tilde{e}_{t+1}^{j}$. From equations (19) and (20) it follows that the covariance in equity return premiums $\operatorname{Cov}\left(\tilde{e}^{i}, \tilde{e}^{j}\right)$ can be decomposed as follows:

$$
\begin{aligned}
\operatorname{Cov}\left(\tilde{e}^{i}, \tilde{e}^{j}\right) & =\operatorname{Cov}\left(\tilde{e}_{d}^{i}, \tilde{e}_{d}^{j}\right)-\operatorname{Cov}\left(\tilde{e}_{d}^{i}, \tilde{e}_{r}^{j}\right)-\operatorname{Cov}\left(\tilde{e}_{d}^{i}, \tilde{e}_{e}^{j}\right)-\operatorname{Cov}\left(\tilde{e}_{d}^{i}, \tilde{e}_{q}^{j}\right) \\
& -\operatorname{Cov}\left(\tilde{e}_{r}^{i}, \tilde{e}_{d}^{j}\right)+\operatorname{Cov}\left(\tilde{e}_{r}^{i}, \tilde{e}_{r}^{j}\right)+\operatorname{Cov}\left(\tilde{e}_{r}^{i}, \tilde{e}_{e}^{j}\right)+\operatorname{Cov}\left(\tilde{e}_{r}^{i}, \tilde{e}_{q}^{j}\right) \\
& -\operatorname{Cov}\left(\tilde{e}_{e}^{i}, \tilde{e}_{d}^{j}\right)+\operatorname{Cov}\left(\tilde{e}_{e}^{i}, \tilde{e}_{r}^{j}\right)+\operatorname{Cov}\left(\tilde{e}_{e}^{i}, \tilde{e}_{e}^{j}\right)+\operatorname{Cov}\left(\tilde{e}_{e}^{i}, \tilde{e}_{q}^{j}\right) .
\end{aligned}
$$

This decomposition allows us to analyze whether the rise in equity return premium comovement was due to a rise in the comovement of dividend news $\operatorname{Cov}\left(\tilde{e}_{d}^{i}, \tilde{e}_{d}^{j}\right)$, risk-free

\footnotetext{
${ }^{10}$ Note that while the general setup follows Ammer and Mei (1996), the term $\tilde{e}_{r, t+1}$ refers to foreign log real interest rates here, instead of domestic log real rates as in Ammer and Mei (1996). This change allows us to investigate the relative importance of monetary policy synchronization in the synchronicity of equity return premiums.
} 
rate news $\operatorname{Cov}\left(\tilde{e}_{r}^{i} \tilde{e}_{r}^{j}\right)$, or return premium news $\operatorname{Cov}\left(\tilde{e}_{e}^{i}, \tilde{e}_{e}^{j}\right)$.

Note, that in contrast to the comovement analyses presented in the main text, which have looked at equity prices, the covariance analysis presented here directly looks at the comovement in equity return premiums. The results of the two approaches are comparable in that they both indicate the extent to which international comovement in equities can be accounted for by fundamentals - dividends and risk-free rates - and how much must be attributed to other factors - risk appetite, or news about future return premiums.

\section{The VAR model}

In order to compute the variance decomposition (21) we need estimates of the various news terms in equations (19) and (20). A VAR model serves this purpose. The assumption is that changes in expectations due to new information arriving between $t$ and $t+1$ can be isolated through the VAR model. We estimate bilateral VARs on the basis of the following variables: $\log$ equity return premiums $e_{i, t}, e_{j, t}, \log$ real interest rates $r_{i, t}, r_{j, t}$, dividend-price ratios $\delta_{i, t}, \delta_{j, t}$ and the first differences of the log bilateral real exchange rate $\Delta q_{t}$. Collecting these variables in the vector $z_{t}=\left(\begin{array}{llllllll}e_{t}^{i} & r_{t}^{i} & \delta_{t}^{i} & e_{t}^{j} & r_{t}^{j} & \delta_{t}^{j} & q_{t}^{j}\end{array}\right)^{T}$ the VAR model for $z_{\boldsymbol{t}+\mathbf{1}}$ in companion form is

$$
z_{t+1}=A z_{t}+\epsilon_{t+1}
$$

where $A$ is the VAR parameter matrix and $\epsilon$ contains the error terms. The inclusion of variables from countries $i$ and $j$ enables us to study the linkage between both countries.

The equity return premium model summarized by equations (19) and (20) imposes a tight set of cross-equation restrictions on the VAR. On the basis of these and the estimated VAR we compute each of the news components in equations (19) and (20) for each bilateral country-pair $i, j$. For this purpose we define picking vectors $g_{k}$ (row $k$ of the identity matrix) that select the relevant rows from the VAR system:

$$
\begin{gathered}
\tilde{\boldsymbol{e}}_{t+1}^{m}=\boldsymbol{g}_{1}^{m} \boldsymbol{\epsilon}_{t+1}, \quad m=i, j \\
\tilde{\boldsymbol{e}}_{e, t+1}^{m}=\boldsymbol{g}_{1}^{m} \rho_{m} \boldsymbol{A}\left(\boldsymbol{I}-\rho_{m} \boldsymbol{A}\right)^{-1} \boldsymbol{\epsilon}_{t+1}, \quad m=i, j
\end{gathered}
$$




$$
\begin{gathered}
\tilde{\boldsymbol{e}}_{r, t+1}^{m}=\boldsymbol{g}_{2}^{m}\left(\boldsymbol{I}-\rho_{m} \boldsymbol{A}\right)^{-1} \boldsymbol{\epsilon}_{t+1}, \quad m=i, j \\
\tilde{\boldsymbol{e}}_{q, t+1}^{j}=\boldsymbol{g}_{3}^{j}\left(\boldsymbol{I}-\rho_{j} \boldsymbol{A}\right)^{-1} \boldsymbol{\epsilon}_{t+1}, \\
\tilde{\boldsymbol{e}}_{d, t+1}^{i}=\tilde{\boldsymbol{e}}_{t+1}^{i}+\tilde{\boldsymbol{e}}_{r, t+1}^{i}+\tilde{\boldsymbol{e}}_{e, t+1}^{i}, \\
\tilde{\boldsymbol{e}}_{d, t+1}^{j}=\tilde{\boldsymbol{e}}_{t+1}^{j}+\tilde{\boldsymbol{e}}_{r, t+1}^{j}+\tilde{\boldsymbol{e}}_{e, t+1}^{j}+\tilde{\boldsymbol{e}}_{q, t+1}^{j},
\end{gathered}
$$

We set $\rho$ to $0.96 .{ }^{11}$ We can use the thus calculated news components in order to determine whether correlated dividend news $\left(\tilde{e}_{d}\right)$, monetary policy news $\left(\tilde{e}_{r}\right)$ or news about future equity return premiums $\left(\tilde{e}_{e}\right)$ have historically been most important in driving the comovement in international equity return premiums. ${ }^{12}$

\section{Covariance decomposition}

Table A.I shows the covariance decomposition for a pre-WW2 sample, a post-WW2 sample, as well as a post-1980 sample zooming in on the period of high equity price synchronization. The top row states the equity return premium covariance in our sample, and all following rows state the median bilateral component-covariances.

Clearly equity return premium covariance has increased over time, from 1.61 in the pre-WW2 sample to 1.99 in the post-WW2 sample, and 3.48 in the post-1980 sample. Among its components, dividend news covariance is the largest. However, dividend covariance has neither increased, nor decreased substantially over time. One covariance component that clearly increases over time is the covariance in news about future return premiums, which roughly doubles in size in the post-1980 sample.

Covariance in risk-free rate news exhibits a downward trend over time. This is consistent with many countries moving towards a floating exchange rate regime after the end of the Bretton Woods system of fixed exchange rates. As a consequence international risk-free rate covariance explains little of the covariance in return premiums after 1980.

\footnotetext{
${ }^{11}$ This value is directly gleaned from the data according to $\rho_{i}=\left(1+\exp \left(\overline{\delta_{i}}\right)\right)$, with $\overline{\delta_{i}}$ denoting the mean of country $i$ 's $\log$ dividend-price ratio. For our annual data the values for $\rho$ concentrate around 0.96 .

${ }^{12}$ All bilateral VARs have been estimated with one lag, which is our preferred lag order given the relatively short time span covered by the subsamples we are interested in.
} 
Table A.x: Decomposition of the covariance in equity return premiums

\begin{tabular}{lrrr}
\hline \hline & Pre-WW2 & Post-WW2 & Post-1980 \\
\hline Cov(equity return premiums) & $\mathbf{1 . 6 1}$ & $\mathbf{1 . 9 9}$ & 3.48 \\
& & & \\
Cov(dividends) & $\mathbf{1 . 4 2}$ & $\mathbf{1 . 3 6}$ & $\mathbf{1 . 5 6}$ \\
-Cov(dividends, risk-free rate) & -0.36 & $\mathbf{- 0 . 2 7}$ & 0.1 \\
-Cov(dividends, future return) & $\mathbf{- 0 . 4 4}$ & $\mathbf{0 . 4 1}$ & 0.1 \\
-Cov(dividends, real exchange rate) & 0.16 & 0.03 & 0.03 \\
& & & \\
-Cov(risk-free rate, dividends) & -0.46 & $\mathbf{- 0 . 2}$ & 0.13 \\
Cov(risk-free rates) & $\mathbf{0 . 5 4}$ & $\mathbf{0 . 3 4}$ & $\mathbf{0 . 2 7}$ \\
Cov(risk-free rate, future return) & -0.07 & -0.02 & $\mathbf{- 0 . 2 8}$ \\
Cov(risk-free rate, real exchange rate) & 0.14 & -0.03 & -0.01 \\
& & & \\
Cov(future return, risk-free rate) & $\mathbf{0 . 3 2}$ & $\mathbf{- 0 . 2 9}$ & 0.01 \\
-Cov(future return, dividends) & 0.01 & 0.1 & $\mathbf{0 . 4}$ \\
Cov(future returns) & $\mathbf{0 . 5 2}$ & $\mathbf{0 . 6}$ & $\mathbf{1 . 2 3}$ \\
Cov(future return, real exchange rate) & -0.16 & -0.04 & -0.06 \\
\hline \hline
\end{tabular}

Notes: Bold type - 95\% significance-level based on cross-sectionally block-bootstrapped confidence bands. All covariances are shown with the sign in which they enter the covariance in equity return premiums according to equation (21). Thus, summing up rows two to 13 yields the covariance in row one. All covariances have been rescaled by a factor of 100 . Median of bilateral covariances.

Finally, an absolute decrease in some cross-covariance terms, such as the covariance between dividends and risk-free rates, also contributed to the increase in equity return premium comovement.

Overall, the VAR decomposition confirms our earlier result, that neither dividends, nor risk-free rates can explain the late 2oth century surge in equity comovement. Instead it is risk appetite or, put in terms of the terminology used here, revisions to expected future return premiums, that are the primary explanation for the increasing comovement of equities.

\section{International response to U.S. risk-free rate changes}

By extending the VAR framework introduced above it becomes possible to trace the effects of U.S. monetary policy on return premiums, dividend-price ratios and risk-free rates, 
within a framework that acknowledges that ex-post realized variables can deviate from their ex-ante expected counterparts. This is achieved by incorporating U.S. interest rate policy innovations $\Delta R_{t}^{U S}$ into the VAR system (see Bernanke and Kuttner, 2005):

$$
z_{t+1}=A z_{t}+\phi \Delta R_{t}^{U S}+\epsilon_{t+1} .
$$

As our indicator for U.S. short-term rate innovations we use the residuals from a Taylor rule regression of U.S. real short-term rate changes on changes in U.S. real per capita GDP, U.S. CPI inflation, and U.S. real stock prices, as well as one lag of each regressor. The responses of international equity return premiums, dividend-price ratios, and real short-term rates can then be calculated as $A^{k} \phi$.

Figure A.15 displays the resulting impulse response functions for the full sample, as well as the post-1980 sample of high equity return premium co-movement. For the full sample dividends and risk-free rates react to U.S. monetary policy innovations, but not equity return premiums. In contrast, after 1980, equity return premiums exhibit a marked response. International risk-free rates respond less after 1980, than before, while the dividend-price ratio responds similarly in the full- and the post-1980 samples.

In sum, these findings support the evidence presented earlier, which suggests that the effect of U.S. monetary policy on international equity return premiums has gained strength in the past few decades.

\section{Explaining the reaction to U.S. risk-free rate changes}

We can also decompose the effect of U.S. rate innovations on equity return premiums in order to determine whether U.S. monetary policy affects international return premiums through revisions in expectations about future return premiums, dividends or risk-free rates. This can be achieved by multiplying equations (23) to (25) with $\phi$, the vector describing the contemporaneous response of all variables in $z$ to U.S. risk-free rate innovations. Accordingly, the response of the return premium news of country $i$ is

$$
\boldsymbol{g}_{1}^{i} \rho_{i} \boldsymbol{A}\left(\boldsymbol{I}-\rho_{i} \boldsymbol{A}\right)^{-1} \boldsymbol{\phi},
$$

and the response of real risk-free interest rate news is

$$
\boldsymbol{g}_{2}^{i}\left(\boldsymbol{I}-\rho_{i} \boldsymbol{A}\right)^{-1} \boldsymbol{\phi} .
$$


Figure A.15: Response to $+1 p p t$ U.S. policy rate increase
(a) Full sample
(b) Post-1980
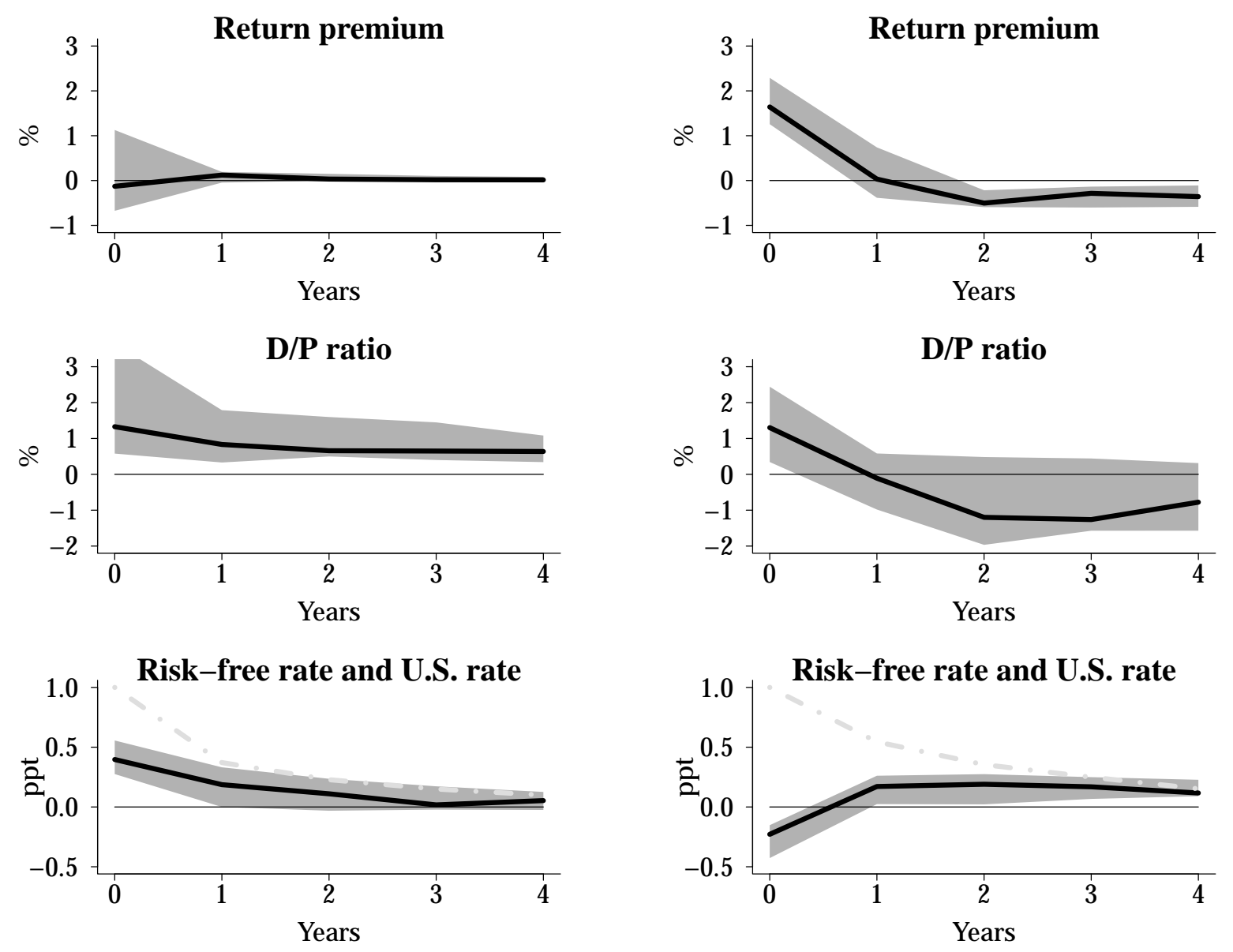

Notes: Median bilateral impulse response functions to +1ppt increase in U.S. interest rates. Dashed gray - U.S. short-term real risk-free rate own response. 95\% interval based on cross-sectional block-bootstrap procedure over bilateral country-pairs. 
Table A.2: The impact of U.S. monetary policy on dividends, interest rates and future premiums

\begin{tabular}{lrr}
\hline \hline & Full sample & Post-1980 \\
\hline Current return premium & $\mathbf{0 . 7 6}$ & $\mathbf{1 . 9 9}$ \\
& & \\
-Future return premiums & $-\mathbf{0 . 5 4}$ & $\mathbf{1 . 9 7}$ \\
-Risk-free rate & $-\mathbf{0 . 4 8}$ & $-\mathbf{0 . 9 8}$ \\
Dividends & $\mathbf{1 . 7 8}$ & $\mathbf{1 . 0 0}$ \\
\hline \hline
\end{tabular}

Notes: Bold type - 95\% significance-level based on cross-sectionally block-bootstrapped confidence bands. All components are shown with the sign in which they enter the current return premium according to equation 19.

In accordance with equation (27) the response of the present value of expected future dividends is

$$
\boldsymbol{g}_{1}^{i} \boldsymbol{\phi}+\boldsymbol{g}_{1}^{i} \rho_{i} \boldsymbol{A}\left(\boldsymbol{I}-\rho_{i} \boldsymbol{A}\right)^{-1} \boldsymbol{\phi}+\boldsymbol{g}_{2}^{i}\left(\boldsymbol{I}-\rho_{i} \boldsymbol{A}\right)^{-1} \boldsymbol{\phi} .
$$

Table A.2 displays the median response over all 16 country-pairs for the full sample, and the post-1980 sample. The post-1980 results indicate that revisions in the expectation about future return premiums explains most of the current return premium response. News about dividends and risk-free rates play smaller roles. In contrast, over the full sample revisions in the expectation about future dividends explains most of the current return premium response, while news about future returns and risk-free rates play a smaller role.

This confirms our earlier finding based on another methodology. The post-1980 increase in international equity comovement was driven by factors other than dividends and risk-free rates. 